21.2

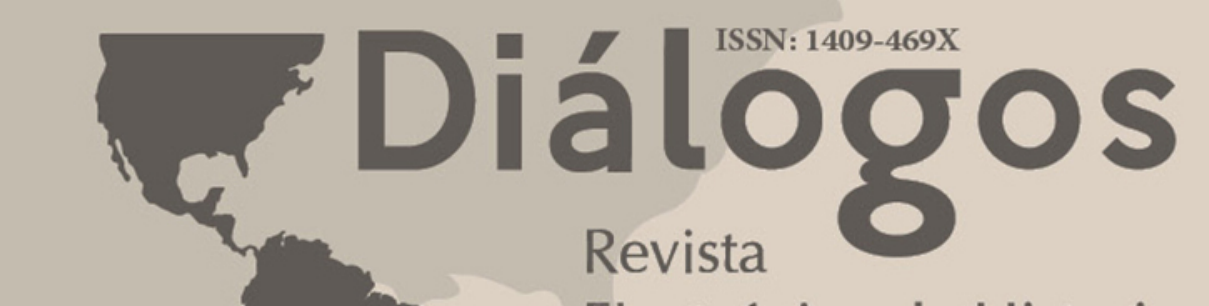

Electrónica de Historia

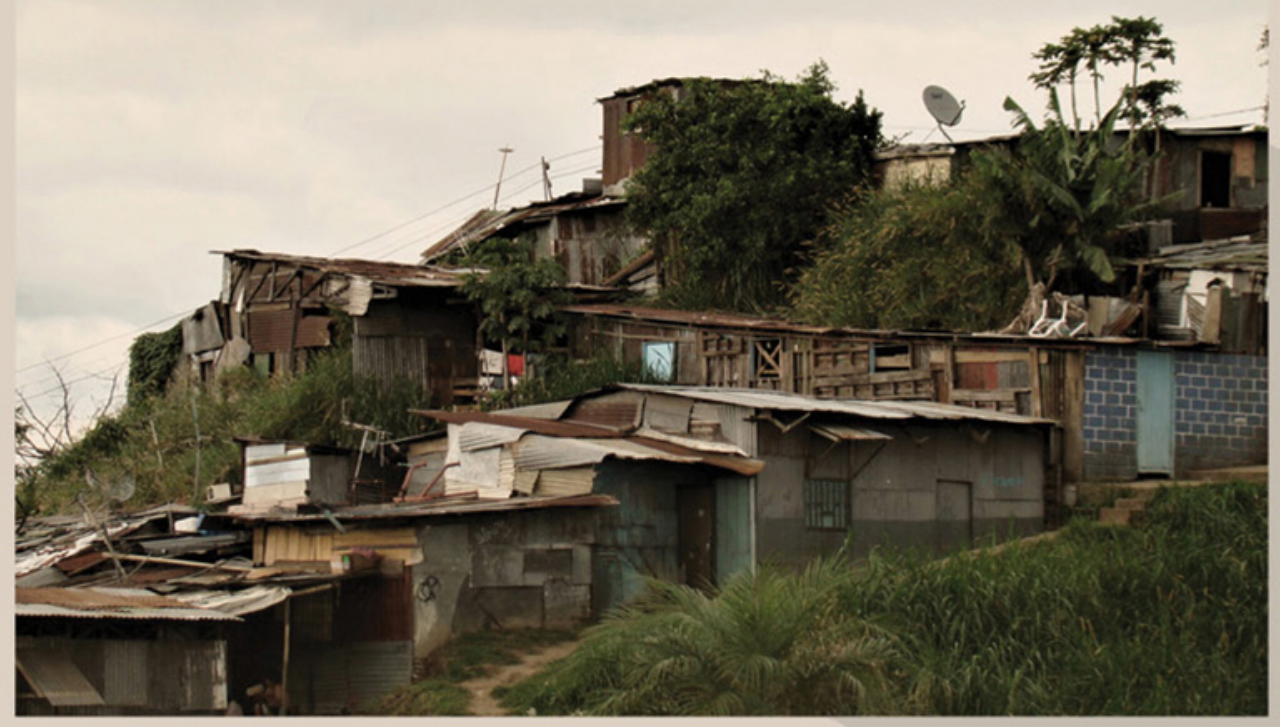

Centro de Investigaciones Históricas de América Central. Universidad de Costa Rica Julio-diciembre 2020

url: http://revistas.ucr.ac.cr/index.php/dialogos/index
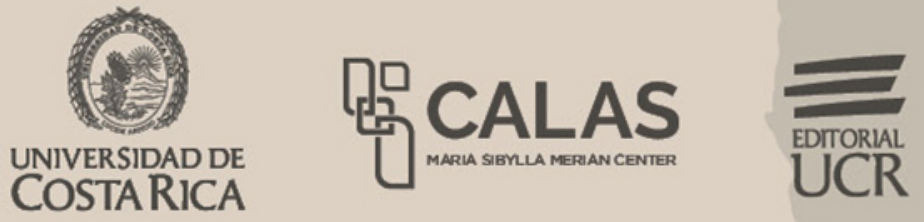


\title{
LAS VENAS ABIERTAS DE AMÉRICA LATINA EN LA ERA DEL ANTROPOCENO: UN ESTUDIO BIOFÍSICO DEL COMERCIO EXTERIOR (1900-2016)
}

\author{
Juan Infante-Amate \\ Alexander Urrego Mesa \\ Enric Tello Aragay
}

\begin{abstract}
Resumen
América Latina ha desempeñado, y sigue desempeñando, un papel clave en el suministro global de recursos naturales. La mayoría de sus economías son exportadoras netas de productos primarios con poco valor añadido mientras que importan bienes manufacturados a precios más elevados. Existe un consenso generalizado entre investigadores de diferentes disciplinas en que este patrón de especialización comercial tiene implicaciones muy negativas para el desarrollo económico, el medio ambiente y, en general, para el bienestar de los habitantes de la región. Sin embargo, no se cuenta con ningún trabajo empírico sobre la contribución total de América Latina al resto de regiones del mundo. Siguiendo la metodología de la Contabilidad del Flujo de Materiales, se estima el comercio físico y el comercio monetario en 16 economías latinoamericanas entre 1900 y 2016.

Palabras clave: metabolismo social, intercambio ecológico desigual, globalización, contabilidad del flujos de materiales, América Latina, comercio, balanza comercial, globalización, economía, recursos naturales
\end{abstract}

Juan Infante-Amate - Universidad Pablo de Olavide de Sevilla, Sevilla, España. Profesor en el Departamento de Geografía, Historia y Filosofía. Contacto: jinfama@upo.es ORCID: https://orcid.org/0000-0003-1446-7

Alexander Urrego Mesa - Universidad de Barcelona, Barcelona, España. Estudiante predoctoral del Departamento de Historia Económica, Instituciones, Política y Economía Mundial.Contacto: alex.urrego.mesa@ub.edu ORCID: https://orcid.org/0000-0002-8256-0321

Enric Tello Aragay - Universidad de Barcelona, Barcelona, España. Catedrático del Departamento de Historia Económica, Instituciones, Política y Economía Mundial.

Contacto: tello@ub.edu

ORCID: http://orcid.org/0000-0002-4970-1524 


\title{
OPEN VEINS OF LATIN AMERICA IN THE ANTHROPOCENE: A BIOPHYSICAL STUDY ON FOREIGN TRADE
}

\begin{abstract}
Latin America has long played a key role in the global provision of natural resources. Most of the continent's economies are low-value, primary-product net exporters while they import manufactured goods at a high price. There is a general agreement among researchers from various fields that this pattern of specialize trade has very negative implications for economic development, the environment, and the local population wellbeing. Yet, there is little empirical evidence on the total contribution of Latin America to the rest of the world's regions. Drawing on Material Flow Accounting methodology, this paper estimates physical and monetary trade in 16 Latin American economies between 1900 and 2016.
\end{abstract}

Keywords: social metabolism, ecologically unequal exchange, globalization, material flow accounting, Latin America, trade, trade balance, globalization, economy, natural resources 


\section{INTRODUCCIÓN}

América Latina ha desempeñado históricamente un papel clave en el suministro global de recursos naturales. Con discontinuidades históricas y geográficas, la mayoría de sus economías han sido exportadoras netas de productos primarios con poco valor añadido mientras que han tendido a importar bienes manufacturados a precios más elevados (Russi et al., 2008; Williamson, 2011; West \& Schandl, 2013). Aunque los debates sobre la naturaleza y el impacto de la inserción de América Latina en el comercio mundial siguen abiertos (p.ej. ver Stern, 1988; Topik, Marichal \& Frank, 2006), existe un consenso generalizado entre investigadores de diferentes disciplinas en señalar que este patrón de especialización comercial tiene implicaciones negativas para el desarrollo económico, el medio ambiente y, en general, para el bienestar de los habitantes de la región (Prebisch, 1981; Ross, 1999; Sachs \& Warner, 2001; Williamson, 2011; Hornborg, 2012; Bértola \& Ocampo, 2013).

Uno de los textos que caracterizó con más éxito (aunque no necesariamente con más rigor) el carácter extractivista de las economías latinoamericanas dentro del sistema económico global fue Las venas abiertas de América Latina de Eduardo Galeano, que rescatamos para dar título a este trabajo. Aunque se publicó hace ya casi medio siglo (en 1971), y sus tesis principales han sido cuestionadas desde diferentes ámbitos, su legado es inmenso y sigue siendo un texto referencial dentro y fuera de la academia. El trabajo, más divulgativo que académico, era representativo de las inquietudes de la izquierda académica del momento, fascinada por los análisis dependentistas de la CEPAL y por las incipientes teorías del 'sistema mundo'. Con base en una extensa revisión de literatura el autor recogía evidencias fragmentarias del carácter extractivo de las diferentes realidades latinoamericanas, desde Potosí hasta la explotación de petróleo en el siglo XX. Sin embargo, la base empírico-cuantitativa que sostenía este trabajo (la disponible en aquel momento) era muy limitada. Aunque documentaba sobradamente el carácter periférico de las economías latinoamericanas, así como los impactos asociados a este tipo de especialización, quedaban abiertas muchas preguntas que hoy, con los desarrollos metodológicos actuales, podemos responder de manera más robusta: ¿hasta qué punto estaban realmente 'abiertas' las venas de América Latina? ¿cómo ha cambiado la hemorragia a lo largo del tiempo? ¿ existen diferencias intrarregionales tanto en el nivel extractivo como en el tipo de especialización? Y, no menos importante, ¿hacia dónde fluyen los recursos naturales de América Latina?

Es importante dejar claro que en las últimas décadas numerosos investigadores se han ocupado de estos temas, principalmente desde perspectivas histórico-económicas e histórico-ambientales ${ }^{2}$, realizando contribuciones sobresalientes. Sin embargo, a pesar de los enormes avances que han tenido lugar, aún seguimos sin contar con ningún trabajo que ofrezcan una visión de conjunto sobre el papel de América Latina en el suministro global de recursos y sobre su impacto en la región. 
La mayoría de los estudios publicados tienen a centrarse en los estudios de caso, tanto a nivel geográfico como a nivel de producto o sector.

Responder a estas preguntas resulta de interés en un momento como el actual, en el que tanto la agenda política como la agenda académica están focalizadas en estudiar los orígenes, la evolución, el impacto, las causas y las responsabilidades del cambio global. Buena parte de los impactos ambientales a escala planetaria tienen lugar en América Latina: desde la deforestación, a la pérdida de biodiversidad, la alteración de los flujos bioquímicos o las emisiones asociadas a los cambios de uso del suelo (Houghton, Lefkowitz \& Skole, 1991; Hurtt et al., 2011; Lassaletta et al. 2014). Todos estos impactos se incluyen entre los conocidos 'límites planetarios' que, de ser sobrepasados, podrían poner en cuestión nuestra supervivencia como especie (Roksctron...). En otras palabras, profundizar en la dimensión material y económica del comercio de América Latina no solo nos sirve para contribuir a debates clásicos como los relativos al impacto del comercio internacional en la región o su carácter dependensdista que siguen contando con buena salud, sino también para arrojar luz sobre sobre uno de los grandes temas de nuestros días: el surgimiento del Antropoceno, la nueva era geológica dominada por los humanos (Steffen et al., 2015).

Por fortuna, en los últimos años se han llevado a cabo avances metodológicos muy importantes, sobre todo relativos a la capacidad de computación de datos y a la digitalización de fuente históricas que nos permiten analizar estos fenómenos a gran escala. Las principales contribuciones en esta dirección han surgido desde la Economía Ecológica, la rama biofísica de la economía ${ }^{3}$, donde se han desarrollado diferentes metodologías ad hoc para dimensionar la extracción, la circulación y el consumo de recursos. Una más extendidas es la Contabilidad del Flujo de Materiales (en adelante MFA, por sus siglas en inglés), que hoy en día forma parte de la contabilidad ambiental de muchos países del mundo, así como de importantes organismos internacionales como la OCDE, Naciones Unidas o Eurostat (Fischer-Kowalski et al., 2011; Schandl et al., 2017). En la actualidad, se han publicado estimaciones MFA para la mayoría de las economías nacionales, incluyendo las latinoamericanas, entre 1970 y la actualidad. De hecho, existen numerosos análisis monográficos sobre América Latina a nivel regional (West \& Schand1, 2013) por grupos de países (Russi et al., 2008; Dorninger \& Eisenmenger, 2016; Samaniego, Vallejo \& Martíez-Alier, 2017; Crespo-Marín \& Pérez Rincón, 2019) o para estudios nacionales específicos como Colombia (Pérez Rincón, 2006; Vallejo, Pérez Rincón \& Martinez-Alier, 2011), Chile (Giljum, 2004), Ecuador (Vallejo, 2010), Argentina (Manrique et al., 2013) y México (González Martínez \& Schandl, 2008). ${ }^{4}$

Los resultados derivados de estas recientes investigaciones han sido decisivos para arrojar luz sobre debate de las 'venas abiertas' y para caracterizar el papel de América Latina en el ascenso del Antropoceno. Sus principales contribuciones pueden resumirse así:

1) A nivel global, América Latina (junto a Asia Central) es la región del mundo con mayores exportaciones netas de materiales por habitante, superando la tonelada 
por habitante y año. Aunque existen otras regiones que son exportadoras netas de materiales, como Oriente Próximo o África, ninguna de ellas aporta tantos recursos per cápita al resto del mundo (Schaffartzik et al., 2014).

2) Entre las regiones exportadoras netas, América Latina es la principal suministradora de biomasa y de minerales metálicos. En el resto de las economías periféricas los combustibles fósiles dominan en el conjunto de los materiales exportados. El perfil exportador de América Latina es mucho más diversificado y, por tanto, asume impactos ambientales mucho más variados, incluyendo tanto los relacionados con el extractivismo mineral como con el extractivismo agrario (West \& Schand1, 2013; Schaffartzik et al., 2014).

3) Desde la década de 1970 la extracción de materiales se ha multiplicado por cuatro, pasando de c. 2000 millones de toneladas (Mt) a más de 8000 Mt. Alrededor de un $10 \%$ de esa extracción se destina al comercio internacional (West \& Schandl, 2013). El crecimiento en la extracción es muy superior a la media global, por lo que el papel de América Latina en la apropiación global de recursos es cada vez mayor (Krausmann et al., 2009). En otras palabras, después de la publicación de 'las venas abiertas', el carácter extractivo de América Latina ha seguido creciendo en términos absolutos y relativos (a la media global).

4) Solo los estudios de caso nacionales ofrecen información sobre la intensidad material de las exportaciones o sobre la relación de intercambio, esto es, sobre la relación entre el comercio físico y el comercio monetario (p.ej., Pérez Rincón, 2006). Aunque existen importantes divergencias regionales y las tendencias han cambiado a lo largo de la historia, la mayoría de las economías de América Latina importan a mayor precio del que exportan. Dicho de otra forma, su descapitalización material no siempre genera retornos económicos positivos. De hecho, en muchos países de la región coexisten déficits tanto en los balances comerciales físicos como en los monetarios: a pesar de exportar más recursos de los que se importan, no se generan suficientes ingresos para pagar las importaciones (Hall, Leon Pérez \& Leclerc, 2000; Fischer-Kowalski \& Amann, 2001; Russi et al., 2008).

5) Todas estas evidencias han servido para nutrir una de las principales teorías dentro de la Economía Ecológica, la del 'Intercambio Ecológico Desigual' (Rice, 2007; Hornborg, 2012; Dorninger \& Hornborg, 2015). Esta teoría, que supuso una relectura ambiental de las tradicionales interpretaciones del intercambio económico desigual, ha sido nutrida por estudios MFA que evidencian el papel del Sur global como provisor neto de materiales a bajos precios (Giljum \& Eisenmenger, 2004; Common \& Stag1, 2005).

Esta literatura no obstante tiene importantes limitaciones más allá de su sesgo económico-ecológico y la consecuente desatención de algunos debates centrales en otras disciplinas como la historia o la sociología. En primer lugar, presenta un marco temporal estrecho. En el mejor de los casos se ofrece información desde 1970 (West \& Schand1. 2013; WU Vienna, 2020). Las ‘venas’ de América Latina han estado abiertas durante mucho más tiempo. Para comprender un fenómeno histórico es imprescindible dotar de historicidad las bases empíricas con las que construimos nuestras narrativas. 
En segundo lugar, las bases de datos sobre comercio de materiales en América Latina, salvo contadas excepciones (Ricaurte Greene, 2012), no distinguen el comercio bilateral. Dicho de otra forma, aunque se asume que la contribución material de América Latina nutre a los países más desarrollados, lo cierto es que no se cuenta con evidencias que corroboren a nivel agregado esta hipótesis ${ }^{5}$. En este sentido, se suele señalar que hubo una transición hegemónica en las potencias que han controlado el extractivismo latinoamericano: del dominio colonial europeo a la influencia de los EE.UU. (y parcialmente de la URSS). Sin embargo, se desconoce el peso material que ha tenido el norte global en la sustracción de recursos procedentes de América Latina. Esta laguna es tanto más inquietante cuando existen evidencias que apuntan a que, con el cambio de siglo, el eje Asia-Pacífico, liderado por China, está jugando un nuevo papel hegemónico en el extractivismo de América Latina (Ellis, 2009; Muradian, Walter \& Martínez-Alier, 2012) ¿Hasta qué punto es así? ¿Es comparable la influencia oriental en el subcontinente a la tradicional influencia occidental?

La tercera laguna tiene que ver con la pobre relación entre extractivismo e impacto económico. La mayoría de los trabajos que usan la metodología MFA documentan con eficacia la descapitalización material de un país a través de sus balances comerciales físicos, sin embargo, no suelen ofrecer análisis que vinculen el comercio físico con el comercio monetario, por lo que es difícil testar la aseveración de que el continente exporta materiales a un precio más bajo, o con menor valor añadido, del que los importa. Desde la economía sí existe una gran tradición en el estudio de las relaciones de intercambio entre países. En el caso de América Latina este debate, que es de gran importancia, ha girado en torno a la teoría cepalina de la dependencia, que sugería la existencia estructural de una relación de intercambio lesiva (Cardoso, 1977; Hadass \& Williamson, 2003; Blattman, Hwang \& Williamson, 2003; Blattman, Hwang \& Williamson, 2004; Blattman, Hwang \& Williamson, 2007; Williamson, 2008; Ocampo, 2017; Ocampo \& Parra, 2003, 2010; Williamson, 2011). Sin embargo, la teoría económica se ciñe, al decir de Naredo (2010), a la esfera crematística, esto es, a los flujos monetarios asociados al comercio, los cuales no son indicativos del impacto ambiental. La literatura de la relación real de intercambio es poco informativa sobre la degradación ambiental en los países estudiados.

El objetivo de este trabajo es arrojar luz sobre las tres limitaciones que se acaban de señalar. Para ello, siguiendo la metodología MFA, se plantea un estudio de las balanzas comerciales físicas y monetarias para una amplia muestra de países de América Latina (un total de 16), entre 1900 y 2016. La base de datos resultante permitirá responder a las siguientes preguntas de investigación:

i) ¿Cuánto ha contribuido América Latina a la construcción material del mundo moderno en el siglo XX? O, dicho de otra forma, ¿cuál ha sido su papel en el desarrollo del Antropoceno?

ii) ¿Cuáles son los patrones de especialización extractiva y comercial en los diferentes países de la región? 
iii) ¿Cuál es el diferencial de retribución por unidad comerciada y cómo ha evolucionado a lo largo del tiempo y entre socios comerciales?

iv) ¿Cómo ha evolucionado la relación entre el crecimiento económico y la descapitalización material?

Tras esta introducción, el texto se organiza de la siguiente forma. Primero, se detallan la metodología y las fuentes utilizadas. Después se presentan y analizan los principales resultados en una sección que se divide en seis bloques: i) la contribución de América Latina a la economía biofísica global; ii) los diferentes patrones regionales de especialización comercial; iii) las relaciones bilaterales del comercio en unidades físicas; iv) las relaciones de intercambio y el intercambio ecológico desigual; y v) la relación entre comercio físico y crecimiento económico.

\section{NOTAS METODOLÓGICAS}

\section{La contabilidad del flujo de materiales}

La contabilidad del flujo de materiales (MFA) es una herramienta metodológica, harmonizada internacionalmente, que data de finales de la década de 1990 y que hoy está incorporada por las principales agencias estadísticas del mundo. Fue diseñada para suplir las carencias de la Contabilidad Nacional clásica a la hora de informar sobre la presión de la economía en el medio ambiente (Fischer-Kowalski et al., 2011). A pesar de sus reconocidas limitaciones (ver, por ejemplo, Giampietro, 2006), constituye una herramienta útil y didáctica para monitorear el perfil productivo, la especialización comercial y los niveles de consumo de las economías nacionales en términos biofísicos (ver Infante-Amate, González de Molina y Toledo, 2017; Haberl et al., 2019).

En la Figura 1 se recoge una síntesis de los principales indicadores propuestos por la metodología MFA. Por un lado, se contabiliza la 'Extracción Doméstica' (en delante DE, por sus siglas en inglés), que es la cantidad de recursos materiales que son extraídos dentro de la unidad político-territorial analizada. La DE actúa como proxy de la presión doméstica sobre el medio ambiente (Giljum, Dittrich, Lieber \& Lutter, 2014). Por otro lado, se contabiliza el comercio de materiales. La diferencia entre los materiales importados y los materiales exportados se denomina 'Balance Comercial Físico' (en delante PTB, por sus siglas en inglés). Este indicador es un buen proxy de la externalización de los impactos a terceros países (Giljum \& Eisenmenger, 2004). Un PTB positivo indica que una economía importa más bienes materiales de los que exporta, por lo que es demandante neta de recursos. Y viceversa. Finalmente, se contabiliza el 'Consumo Doméstico de Materiales' (en delante DMC, por sus siglas en inglés), que es estimado como la ED más las importaciones menos las exportaciones de materiales, esto es, la ED menos el PTB. 
El DMC recoge el consumo de materiales de los habitantes del territorio analizado, independientemente de donde sean extraídos.

Estos indicadores están disponibles para la mayoría de los países del mundo desde 1970 y han permitido arrojar luz sobre debates muy relevantes como: 1) los puntos calientes globales en la extracción de materiales por tipo de productos; 2) identificar el nivel de consumo de materiales a nivel nacional y la desigualdad del consumo material entre países; 3 ) identificar los territorios que son suministradores netos de materiales y los que son demandantes netos, lo que ha permitido arrojar luz en debates como los del Intercambio Ecológico Desigual y 4); relacionar el consumo de materiales con otros indicadores como el PIB o en IDH, lo que ha permitido analizar hasta qué punto nuestro desarrollo económico y nuestro bienestar material son dependientes del consumo de materiales (Infante-Amate, Toledo \& González de Molina, 2017; Haberl et al., 2019).

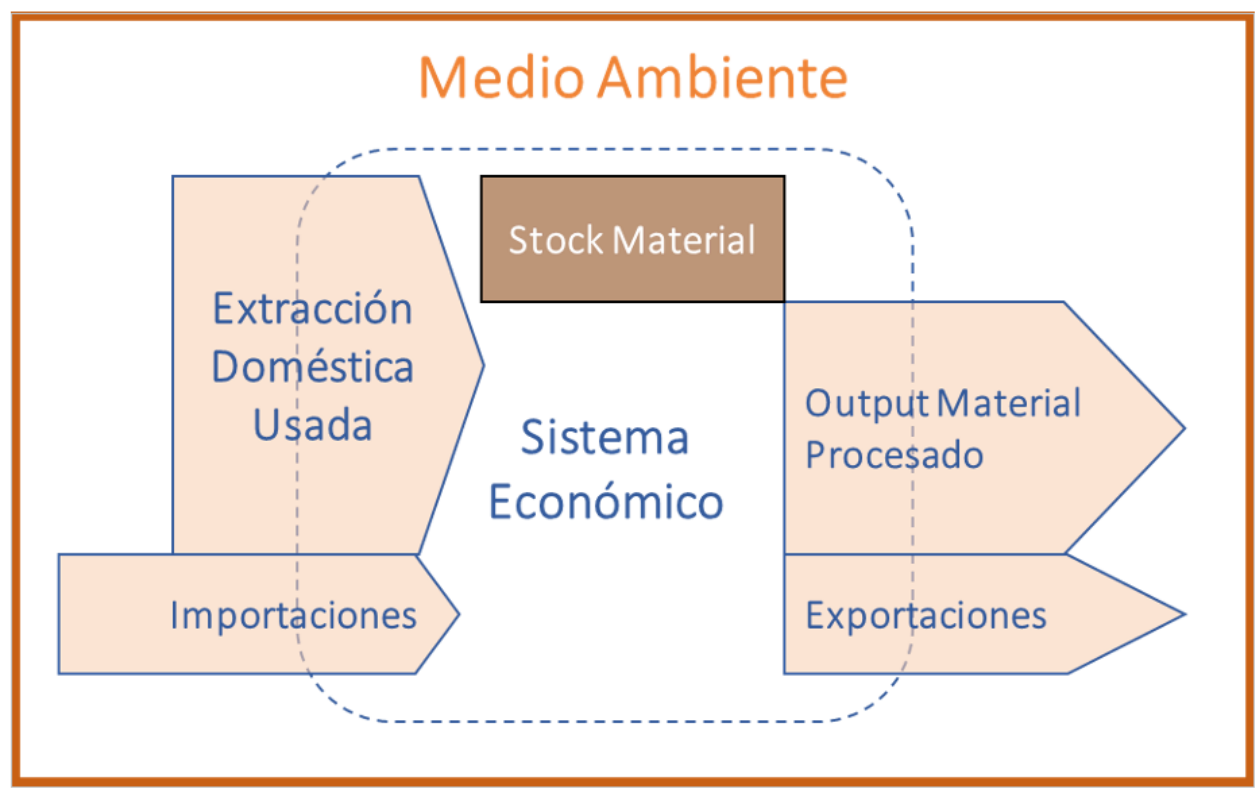

Figura 1. Esquema simplificado de la contabilidad del flujo de materiales. Fuente: adaptado de Eurostat (2018).

\section{Límites del estudio}

Este trabajo se centra exclusivamente en los indicadores de comercio. En particular, se cuantifican las importaciones, las exportaciones y el balance de materiales (PTB) para un total de 16 economías de América Latina para las que ha sido posible compilar información fiable de largo plazo. 
Siguiendo la metodología MFA, los flujos de materiales analizados se agregan en Biomasa, Combustibles Fósiles, Minerales Metálicos y Minerales no Metálicos (Eurostat, 2018). Así, el PTB de cada país (i) se estima como las importaciones ( $M$ ) menos las exportaciones $(X)$ de cada grupo de productos $(j)$ :

$$
P T B_{i}=\sum_{j} M_{j}-X_{j}
$$

Entre 1966 y 2016 se han podido reconstruir las relaciones comerciales bilaterales en cada país distinguiendo un total de 268 socios. Para facilitar el análisis de los resultados se agregan los países estudiados en grupos regionales (ver Tablas 1 y 2 del Anexo Metodológico). En el caso de los países de América Latina se distinguen: México, Centro, Andinos, Brasil y Sur. En el caso de los socios comerciales distinguimos entre: América Latina y Caribe; América del Norte; Europa; África; Asia Central y Occidental; y Asia-Pacífico. Esta última división permite deducir el comercio intrarregional y, por lo tanto, cuantificar el PTB neto de América Latina. Nótese que sin los datos de comercio bilateral no es posible estimar el comercio de América Latina como un todo, ya que si simplemente se agregan las exportaciones y las importaciones de cada país se estaría estimando la suma total de sus exportaciones e importaciones, incluyendo aquellas que se destinan a países de la propia región. Así, excluyendo los países (i) de América Latina y el Caribe, se estima el PTB neto de toda la región de la siguiente forma:

$$
P T B=\sum_{i j} M_{i j}-X_{i j}
$$

También se estiman los balances comerciales monetarios a precios corrientes. Con esta información, se analiza cómo han evolucionado el precio de las importaciones y el precio de las exportaciones por unidad material. La ratio entre estos dos indicadores permite analizar la evolución de las relaciones de intercambio tal como han sido planteadas en otros trabajos desde la Economía Ecológica (Pérez-Rincón, 2006; Samaniego, Vallejo \& Martínez-Alier, 2017; Infante-Amate \& Krausmann, 2019). Tal relación puede notarse así:

$$
R I_{i j}=\sum_{j} \frac{m_{i j}}{x_{i j}}
$$

Siendo $m_{i}$ el valor monetario de cada unidad material importada y $x_{i}$ el valor monetario de cada unidad material exportada (en ambos casos, medida en US $\$ / \mathrm{kg}$ ). $\mathrm{Si}$ el resultado es mayor que la unidad significa que el precio de las importaciones es mayor que el precio de las exportaciones. La lectura económico-ecológica que se hace de este fenómeno es que para mantener equilibrada la balanza comercial es necesario vender más materiales de los que se importan y, por lo tanto, descapitalizarse materialmente. 


\section{Fuentes y procedimiento de cálculo}

Para la reconstrucción del comercio físico y monetario de las economías latinoamericanas seleccionadas para un período tan amplio de tiempo, se han combinado diferentes fuentes documentales. En la Tabla 3 del Anexo Metodológico recogemos un resumen de las mismas para cada caso. Entre 1962 y 2016 la información proviene de la base de datos de comercio de Naciones Unidas (UNCT, desde aquí). UNCT es la única base de datos global que ofrece información del comercio bilateral tanto en unidades físicas como monetarias entre 1962 y la actualidad para la mayoría de los países del mundo. Otras fuentes, como FAOSTAT, solo ofrecen información para los productos agrarios y únicamente distingue el comercio bilateral a partir de 1986, mientras que la de la Organización Mundial del Comercio, con información desde 1948, solo proporciona valores monetarios.

El uso de UNCT, sin embargo, no está exento de problemas. El más relevante es que presenta importantes vacíos de información en, al menos, dos ámbitos: no todos los países aportan información para todos los años y no siempre se ofrece información en unidades físicas (más información en Dittrich \& Bringezu, 2010). En el caso de los años sin información la cobertura en las 16 economías seleccionadas es casi total. De hecho, los países que se han descartado en este estudio (muchos de ellos caribeños) son aquéllos en los que la información era más limitada, tanto en cantidad como en calidad. En 10 de las economías estudiadas, entre las que se incluyen las de mayor tamaño (Brasil y Argentina), hay información para todos los años. En las 6 economías restantes existen ciertas lagunas que nunca superan los 3 años (de un total de 54 años), exceptuando Uruguay, donde no hay información para 8 años. Para cubrir la información no disponible, se ha operado de la siguiente forma: (1) si la falta de información es un año suelto que cae en medio de la serie, la estimación se realiza mediante interpolación lineal y; (2) si la información que no está disponible corresponde a varios años al inicio o al final de la serie, se estima tomando como referencia la variación de otras variables. En el caso de la serie en unidades monetarias, se toma la variación de las importaciones y de las exportaciones en cada país recogidas en la base de datos de la Organización Mundial de Comercio (WTO, 2019). En el caso del comercio físico se utiliza el índice de 'volumen de las exportaciones' y las 'importaciones' disponible en la base de datos MOxLAD (2019) para cada uno de los países analizados. Finalmente, para los productos que no registraban información en unidades físicas, se calculó el valor por unidad física (US\$ $/ \mathrm{kg}$ ) en los países en los que sí hay información disponible y se aplica la media regional del precio por kilogramo a los datos monetarios.

UNCT ofrece varios niveles de desagregación de la información en la descarga de datos. En este estudio se utiliza el sistema SICT-1 con ' 3 dígitos', ya que es el único que posibilita obtener información entre 1962 y 2016 en una descarga única, permitiendo una desagregación de 182 productos de exportación e importación. Solo para el período 1962-2016, en el que se utiliza UNCT, la base de datos resultante supera los 20 millones de observaciones. 
Para el período 1900-1961 la información está dispersa en diferentes fuentes. En este período solo se estima el comercio físico. La League of Nations (1926/44) ofrece información del comercio físico total para los años de 1913 y de 1920 a 1934 para todos los países excepto Uruguay. Los datos restantes se complementaron con la información de los Anuarios Estadísticos de Comercio Exterior de Argentina, Bolivia, Brasil, Chile, Colombia, Costa Rica, México, Paraguay, El Salvador y Venezuela (ver Tabla 3 en los Anexos) y, cuando no fue posible, se usó el 'índice de volumen' de MOxLAD (2019). De esta forma obtenemos una serie anual entre 1900 y 2016 del comercio físico total por país. Para distinguir los diferentes tipos de materiales utilizamos las series del Instituto Internacional de Agricultura (IIA, 19091947) y de FAO (1948-1961), para el caso de la biomasa; y las estadísticas históricas de Mitchell (2013), que ofrecen información sobre el comercio de combustibles fósiles y minerales para los principales productos y países de la región. En los casos en que no se obtuvo información se asumió la proporción del año más próximo.

Para limitar el impacto de los outliers y para suavizar la tendencia, las series se estiman tomando las medianas móviles quinquenales.

\section{RESULTADOS Y DISCUSIÓN}

\section{La contribución de Latinoamérica a la economía biofísica global}

La Figura 1 muestra el PTB de América Latina entre 1900 y 2016 por tipo de producto. La primera evidencia es que, durante el período analizado, América Latina aparece, sin excepción, como suministradora neta de materiales hacia el resto del mundo, esto es, sus exportaciones son siempre mayores que sus importaciones. El segundo mensaje que sobresale es que el nivel de déficit material no ha dejado de crecer hasta la actualidad. El suministro neto es hoy en día mayor que nunca. En 1900 las exportaciones netas eran 4 millones de toneladas métricas (Mt) y en 2016 ascendieron a $610 \mathrm{Mt}$. El crecimiento, no obstante, no ha sido lineal, lo que nos conduce a la tercera observación: la 'gran aceleración' en el comercio de materiales, tanto en la importación como la exportación, tuvo lugar en la segunda mitad del siglo XX, especialmente desde la década de 1980. La conocida 'gran aceleración' en el consumo de recursos a nivel planetario tuvo lugar tras la Segunda Guerra Mundial y se concentró en los países más ricos (Steffen et al., 2015). No obstante, la contribución de América Latina a este proceso empezó a ser más relevante desde la década de 1980. Hasta esa fecha el aumento en el consumo de materiales en los países más ricos se completó con recursos domésticos o con materiales provenientes de otros países periféricos (Schaffartzik et al., 2014). Durante el período c. 1930-1980 las economías latinoamericanas desarrollaron políticas de ‘sustitución de importaciones’. 
Sin embargo, tras la crisis de la deuda externa y el giro neoliberal de la década de 1980 la mayor parte del continente abandonó estas políticas y puso en práctica, o le fueron impuestas por planes de ajuste de las entidades financieras internacionales (FMI, Banco Mundial y otras), medidas de desregulación y de apertura al comercio internacional, lo que generó un incremento acelerado en las exportaciones globales (Hall, Leon Pérez \& Leclerc, 2000; Bértola \& Ocampo, 2013). En términos materiales, según nuestros datos, las exportaciones totales de materiales pasaron de 7 Mt a 115 Mt entre 1900 y 1980. El gran crecimiento fue posterior: en 2016 las exportaciones ascendían a $1.035 \mathrm{Mt}$.

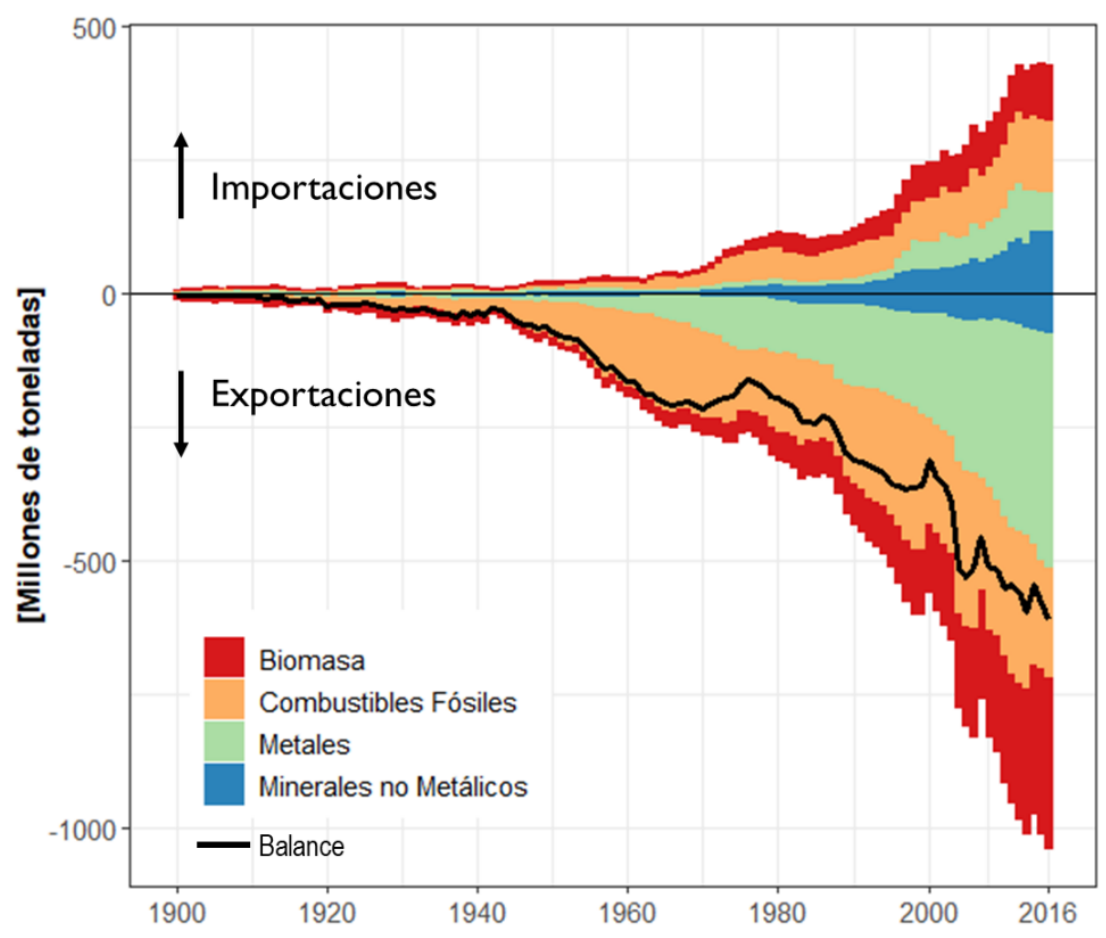

Figura 2. Balance comercial físico (PTB) de América Latina (1900-2016). Fuente: Elaboración propia (ver Patrones regionales de especialización). Nota: Las importaciones son las barras con valor positivo y las exportaciones las barras con valor negativo. La línea negra es el balance.

Entre 1980 y 2016 las exportaciones de América Latina han representado de manera más o menos estable un $10 \%$ de las exportaciones totales globales. Esta cifra es mucho mayor en el caso de la minería metálica. Durante buena parte de las décadas de 1980 y 1990 una de cada tres toneladas exportadas en el mundo provenía de América Latina. En el caso de la biomasa la cifra tambíen supera la media y ha crecido en los últimos años: en la actualidad una de cada cinco toneladas exportadas provinene de la región. Dicho de otra forma, América Latina ha jugado un papel central 
en la segunda fase de la 'gran aceleración'y, en consecuencia, en el aumento dramático del uso de recursos a nivel global que nos ha conducido a una nueva era geológica: el Antropoceno. No todos los países tienen, sin embargo, la misma responsabilidad en este proceso: mientras que unos son grandes consumidores y demandantes netos, otros, como los latinoamericanos, soportan la carga de la transición con beneficios limitados. Esta carga, además, es cada vez mayor: la exportación de materiales de las últimas tres o cuatro décadas puede haber sido mayor que la que ha tenido lugar en toda la historia antes de esa fecha, y, solo las exportaciones de 2015 y 2016, pueden haber superado las que tuvieron lugar durante más de tres siglos de colonialismo. ${ }^{6}$

Una cuarta evidencia que extraemos de la Figura 2 es que la especialización comercial ha cambiado a lo largo de la historia. A principios del siglo XX la biomasa, esto es, los productos agrarios, pecuarios y forestales, eran los principales bienes de exportación. A media que avanzó el siglo XX los combustibles fósiles se convirtieron, con diferencia, en el principal material exportado. En 1952 llegaron a representar tres cuartas partes de todos los materiales exportados. A partir de esa fecha su peso cayó significativamente por dos motivos: primero, por la caída de las exportaciones debido a la aparición de nuevas zonas productoras como Oriente Próximo y, segundo, por la rápida expansión de la minería metálica. Con la llegada del siglo XXI se ha consolidado la exportación de minerales metálicos, principalmente provenientes de Chile y Brasil, pero también de biomasa, que hoy supone un $30 \%$ del total de las exportaciones de la región y ya superan en cantidad a las de los combustibles fósiles.

En la Figura 3 ofrecemos un detalle más pormenorizado de la evolucíon de los balances físicos por tipo de producto. En todos los casos las exportaciones y las importaciones han crecido durante el período estudiado, especialmtene tras la segunda mitad del siglo XX. Observamos que la región es exportadora neta de todo tipo de materiales salvo de minerales no metálicos, con unas importaciones netas acumuladas de $334 \mathrm{Mt}$ entre 1900 y 2016. Esta cifra contrasta con las exportaciones netas acumuladas de los combustibles fósiles (8.795 Mt), los minerales metálicos $(7.839 \mathrm{Mt})$ y la biomasa $(4.045 \mathrm{Mt})$. Como se anunciaba en la introducción, el perfil exportador difiere del de otras regiones periféricas del mundo como Asia Central u Oriente Próximo, donde la mayor parte de las exportaciones son combustibles fósiles.

La diversidad en el tipo de materiales exportados hace que el subcontinente albuergue múltiples problemáticas y conflictos de tipo ambiental. En el caso de los combustibles fósiles se combinan problemas asociados al desarrollo de instituciones disfuncionales y luchas por el control de los beneficios en Venezuela, México o Bolivia (Ross, 2013; Wenar, 2015), al tiempo que se destruyen zonas con gran valor ecológico como en el reciente caso de Yasunni ITT (Larrea \& Warnars, 2009). La extracción minera a gran escala también implica la alteración de ecosistemas de gran valor, como ocurre en las zonas mineras de Brasil, Chile o Perú, pero principalmente contaminación a gran escala de suelos y agua (p.ej, Malm, Pfeiffer, Souza \& Reuther, 1990; Castro \& Sánchez, 2003; Li, 2015). 
Por su parte, el auge del comercio de la biomasa ha estado acompañado de severos procesos de derforestación en algunos de los bosques con más densidad de carbono y más biodiversos del mundo como los de Centro Américo o de la Amazonía (p.ej., Houghton, Lefkowitz \& Skole, 1991; Malhi et al., 2008). El carácter intensivo que caracteriza la agricultura de exportación de América Latina genera importantes problemas de contaminación de los recursos naturales y de intoxicaciones humanas. A modo de ejemplo, Costa Rica conocido por sus fuertes medidas de protección ambiental es el país del mundo con mayor uso de pesticidas por superficie cultivada debido a su especialización agroexportadora en productos que se manejan de manera muy intensiva (según datos de FAOSTAT, ver también Hall, Leon Pérez \& Leclerc, 2000; Galt, 2008). La diversidad en la exportación de materiales en la región se correlaciona bien con la diversidad de conflictos ambientales recogidos por el proyecto EJOLT (2019), en el que se puede corroborar que en América Latina no solo se concentra un volumen muy importante de conflictos ambientales sino que también alberga una amplia diversidad tipológica (Scheidel et al., 2020).

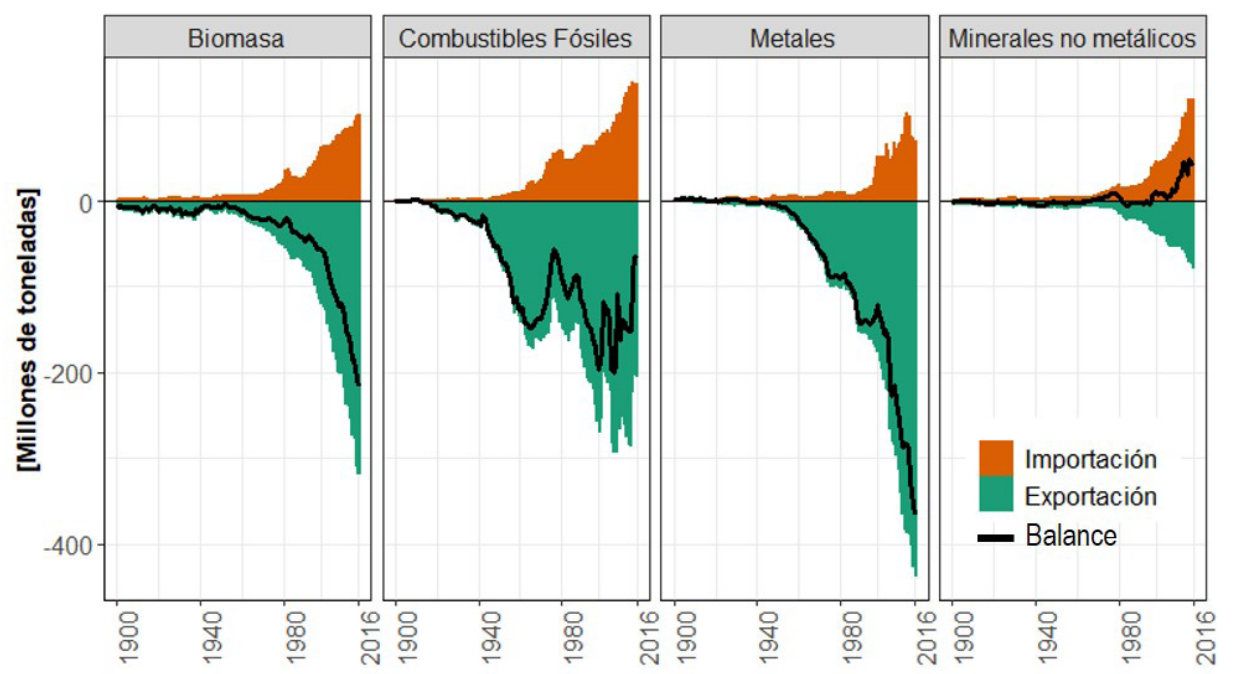

Figura 3. Balance comercial físico (PTB) de América Latina por tipo de material (1900-2016). Fuente: Elaboración propia (ver Patrones regionales de especialización).

\section{Patrones regionales de especialización}

Siguiendo la metáfora de las 'venas abiertas', la hemorragia de reursos naturales presenta cuadros muy diferentes en cada uno los países de América Latina. En las figuras 4 (en valores absolutos) y 5 (en valores per capita) se recopilan los PTB de las 16 economías analizadas. En todas ellas es perceptible una aceleración dramática del comercio en la segunda mitad del siglo XX, especialmente a partir de la década de 1980, 
aunque se pueden indentificar diferentes ritmos de crecimiento así como diferenes patrones de especialización.

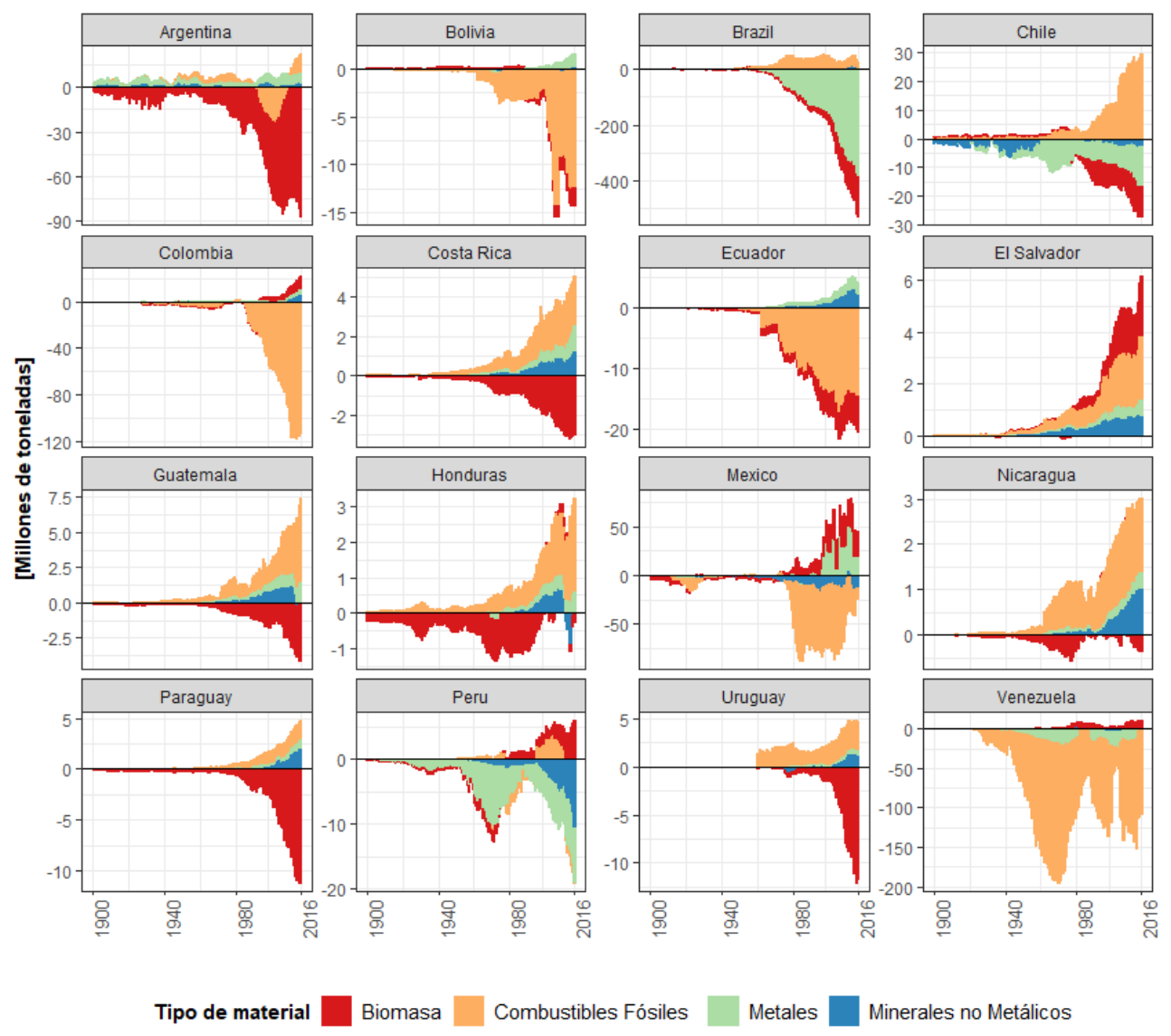

Figura 4. Balance comercial físico (PTB) a nivel nacional por tipo de material (1900-2016). Fuente: Elaboración propia (ver Patrones regionales de especialización). Nota: hemos eliminado la información de Uruguay entre 1900 y 1970 porque baja fiabilidad de la estimación.

Lo primero que se observa es que no todas las economías analizadas son exportadoras netas. De hecho, un total de 5 economías (las centroamericanas) reportan importaciones netas acumuladas para el periodo 1900-2016. El Salvador es la economía más dependiente, con unas importaciones netas de 0,4 toneladas por habitante y año ( $\left(\right.$ hab $\left.^{-1} a_{n} o^{-1}\right)$ en el período estudiado. Además, este país es el único que es importador neto de todo tipo de materiales. Los otros países centroamericanos también son importadores netos, aunque 'solo' en el caso de los minerales y los combustibles fósiles. El resto de economías observadas son, al igual que el conjunto de la región, exportadoras netas, aunque con rangos muy variables que van desde una situación casi balanceada en Uruguay, hasta desequilibrios extremos como el observado en Venezuela con $6,7 \mathrm{t} \mathrm{hab}^{-1} \mathrm{año}^{-1}$. 


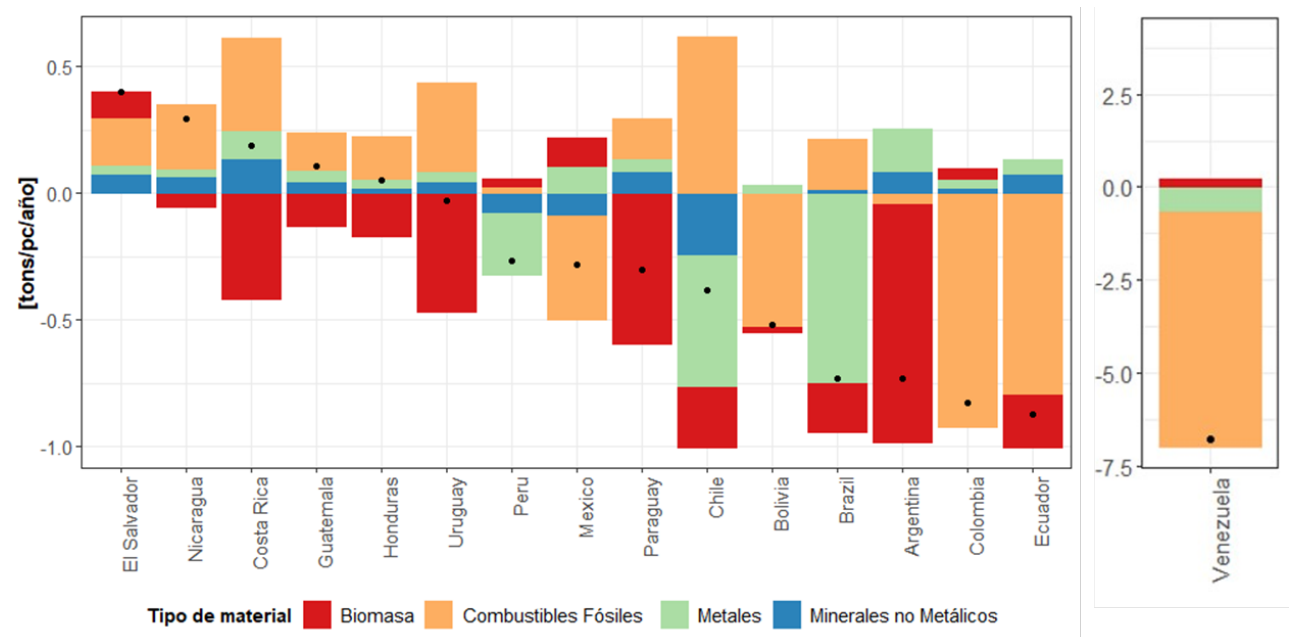

Figura 5. Balance comercial (importaciones menos exportaciones) por habitante y año. Datos del período 19002016. Fuente: Elaboración propia (ver Patrones regionales de especialización). Nota: los datos de Uruguay solo recogen el período 1970-2016.

Igualmente, se encuentran patrones de especialización muy diferenciados. En la Figura 6 se muestra el tipo de especialización comercial en todos los países analizados. En concreto, se evalúa el nivel de importación o exportación neta en los productos extraídos del manto superficial del suelo (biomasa) frente a los productos extraídos del subsuelo (minerales y combustibles fósiles). En esta figura, el perfil exportador se evidencia en valores superiores a la unidad y valores inferiores son indicativos de un perfil importador. Así, se identifican tres grandes grupos subregionales:

1) Países centroamericanos que son importadores netos en general, pero exportadores netos de biomasa. Esto se debe a que, a pesar de ser exportadores netos de biomasa por su especialización en productos tropicales como el café, el cacao o el banano, y de productos ganaderos, son dependientes de combustibles fósiles.

2) Países del Cono Sur, que al igual que el grupo anterior son demandantes netos de subsuelo y exportadores netos de suelo. A diferencia de Centro América, la especialización comercial en productos derivados del suelo, como granos y productos pecuarios, responde adecuadamente a la abundancia relativa del factor tierra sobre el factor trabajo que define la tradición exportadora de los países del Cono Sur ( $\mathrm{O}$ ’Rourke \& Williamson, 1999). La mayor disponibilidad por habitante de superficies aptas para la agricultura hace que el nivel de tierra exportada per cápita también sea superior.

3) Países andinos, principalmente exportadores netos de subsuelo. En Colombia y Venezuela las principales exportaciones son los combustibles fósiles mientras que en Chile y Perú destacan los metales. Este grupo es, no obstante, más heterogéneo. Por un lado, Colombia, Perú y Venezuela son importadores netos de biomasa. México tiene un patrón similar a estos tres países. Por otro lado, Chile, Bolivia y Ecuador, además de ser exportadores de subsuelo, también lo son de suelo. 
Brasil también entraría en este grupo. Estos últimos cuatro países son 'exportadores totales', tanto de productos del subsuelo como de tierra. Destaca Brasil, que es el principal exportador en la región, concentrando casi el $60 \%$ de las exportaciones totales de materiales.

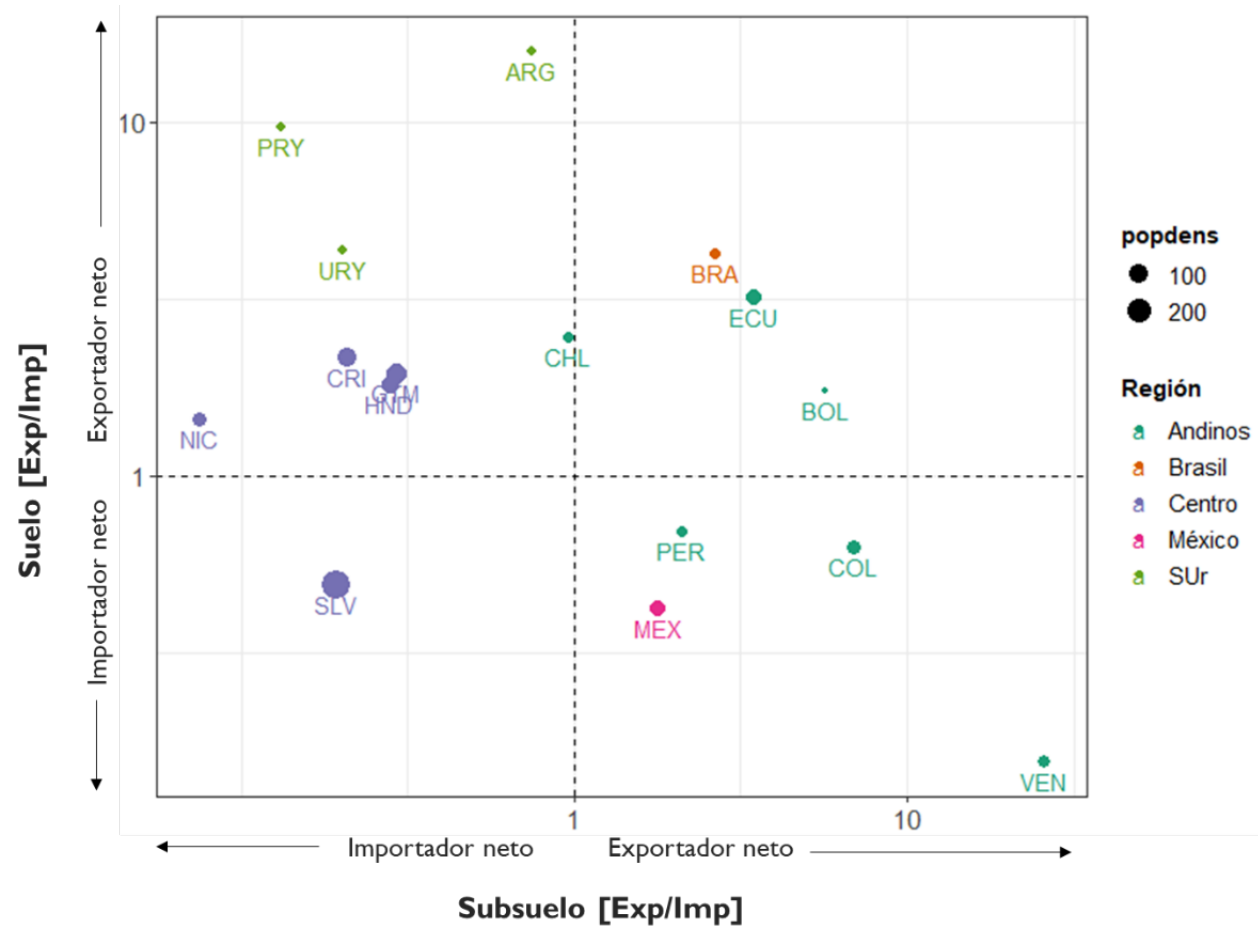

Figura 6. Perfil exportador de los países de América Latina. Los ejes miden las exportaciones dividido por las importaciones. Nota: Valores superiores a 1 indican un perfil exportador. Menos de uno corresponde a un perfil importador. Suelo incluye la biomasa y subsuelo el resto de los materiales.

\section{Los actores globales}

Tal vez uno de los aspectos menos conocidos del comercio de materiales es el de las relaciones bilaterales entre países ¿Hacia dónde fluyen los recursos que exporta América Latina? ¿Han cambiado los países receptores a lo largo de la historia? Es un canon señalar la transición de la influencia colonial europea hacia el dominio norteamericano en el control de las actividades extractivas en la región. Aunque este proceso es bien conocido en el comercio monetario, no se cuenta con estimaciones desde un punto de vista físico a nivel agregado nacional y regional. Lamentablemente, en el caso de las relaciones bilaterales del comercio de materiales la información solo está disponible a partir de 1966. 
Las Figuras 7 y 8 muestran el destino de las exportaciones y el origen de las importaciones de América Latina como región en términos netos. En efecto, Europa y Norte América han acaparado hasta el cambio de siglo casi tres cuartas partes de las exportaciones de América Latina. El flujo de recursos que sale de la región tiene como destino principal un pequeño grupo de países del Norte global que concentran menos del $10 \%$ de la población mundial, pero que suman casi la mitad del PIB mundial (WB, 2019). Esta influencia, que solo se documenta desde la década de 1960 es, con toda seguridad, una continuación de la dominación de las potencias hegemónicas en el subcontinente desde hace siglos: primero, bajo la dominación colonial formal y después, bajo la dominación colonial informal (Ferguson, 2005; Pérez Brignoli, 2018). Los procesos de independencia no trajeron consigo una autonomía plena. Durante la primera globalización la región estuvo dominada por "un imperio informal basado en el libre comercio, el control de rutas navieras, la exportación de capitales y una poderosa ideología de superioridad" (Pérez Brignoli, 2018). En el período de entreguerras y tras la Segunda Guerra Mundial, el comercio de América Latina estuvo nuevamente condicionada por las injerencias de EE.UU. que desde principios del siglo XX multiplicó sus inversiones y sus intereses en la región (Ferguson, 2005; Fontana, 2011). Así, hasta bien entrado el siglo XX, la mayor parte de los recursos materiales fluyeron hacia un grupo pequeño de países industrializados que requerían de materias primas baratas para mantener activas las industrias locales.

En la actualidad, y al contrario de lo que cabría esperar, la relación con Norteamérica ha tendido a balancearse. Esto se debe a que las importaciones desde Estados Unidos han crecido aceleradamente con la llegada del siglo XXI: en 1966 las exportaciones netas de América Latina a Norteamérica eran de $99 \mathrm{Mt}$, en el año 2000 habían bajado a $82 \mathrm{Mt}$ y en la actualidad solo son $2 \mathrm{Mt}$. Este cambio tiene mucho que ver con la pérdida de autosuficiencia alimentaria en un número cada vez mayor de países de América Latina debido a que la creciente expansión de cultivos de exportación desplaza el cultivo local de alimentos básicos e incluso madera que deben importar de Estados Unidos y Canadá, un rasgo particularmente agudo en América Central (Hall, Leon Pérez \& Leclerc, 2000). Esta evolución contrasta con el caso de Europa, en el que las exportaciones netas no han dejado de crecer, pasando de 57 Mt en 1966 a 155 Mt en 2016. 


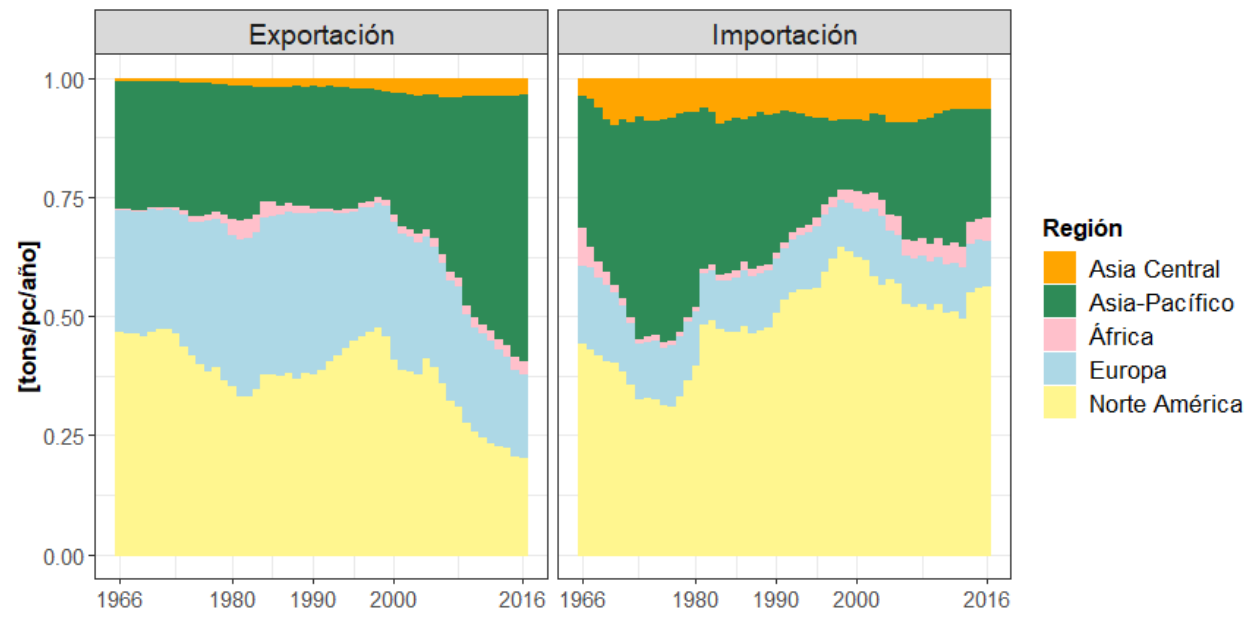

Figura 7. Exportaciones e importaciones de materiales en América Latina distinguiendo el socio comercial. Fuente: Elaboración propia (ver Patrones regionales de especialización).

Con el cambio de siglo se observan dos transformaciones disruptivas en el comercio de materiales latinoamericano. Por un lado, en las relaciones Sur-Sur. Hasta finales del siglo XX, las relaciones con África y Asia Central habían sido balanceadas e incluso hasta negativas, esto es, con importaciones netas. Sin embargo, desde el año 2000, América Latina se ha convertido en exportadora neta de materiales a estas regiones, suministrándole 11 Mt y 12 Mt respectivamente en 2016. 

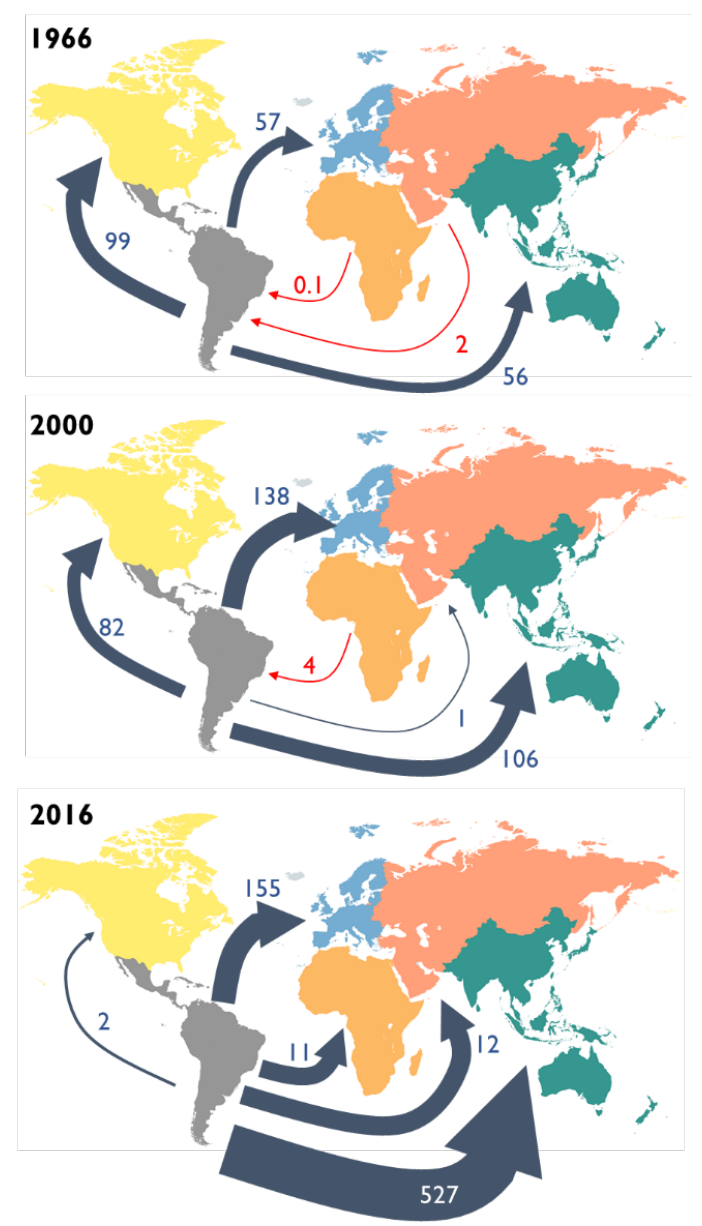

Figura 8. Comercio físico de América Latina. Exportaciones netas (azul) e importaciones netas (rojo). Fuente: Elaboración propia (ver Patrones regionales de especialización).

El cambio más dramático, no obstante, tiene que ver con el eje Asia-Pacífico. Si bien es cierto que la relación comercial ya era notable en la década de 1960, su peso era menor en comparación con Norteamérica y con Europa. Sin embargo, a partir del año 2000 los flujos de materiales hacia la región Asia-Pacífico, principalmente por la demanda de China, creció de manera acelerada. Solo en 2016 las exportaciones netas superaron los $527 \mathrm{Mt}$, un valor sin precedentes históricos.

El resurgir del eje asiático con China a la cabeza, supone un punto de inflexión en la historia de la economía biofísica global. China y algunos países del entorno se han convertido en los 'nuevos talleres del mundo' y, en consecuencia, demandan enormes cantidades de energía y materiales. Hoy en día, China concentra el $21 \%$ de las importaciones totales de materiales, mientras que en 1970 apenas alcanzaba el 0,3\%.

El renacer oriental, como proceso histórico, está aún en una fase muy prematura y es difícil aventurar conclusiones sólidas sobre su impacto en general y en 
el Sur global en particular. Por un lado, se interpreta que el auge de China solo supone un desplazamiento geográfico del poder hegemónico global sin que suponga ninguna oportunidad en los países periféricos. En este sentido algunos autores están documentando cómo este país reproduce las mismas prácticas de dominación que sus predecesores en los países del Sur global: acaparamiento de tierras, explotación laboral o generación de relaciones de intercambio desiguales que perpetúan la especialización en productos básicos (p. ej., Ellis, 2009).

Por otro lado, existen indicios para pensar que la influencia de China en la economía física global es mucho más limitada y se restringe a la de mero intermediario entre los tradicionales centros de poder global (Norte América y Europa) y las economías periféricas. Los trabajos sobre 'huella material' sugieren que buena parte de los productos primarios que recibe China son transformados y luego vendidos, en su mayoría, a países ricos (algunos indicios en Bruckner et al., 2012; Wiedmann et al., 2015). Los países de ingresos más altos siguen, a fin de cuentas, apropiándose de los recursos primarios de América Latina, solo que ahora lo hacen a través de la explotación del trabajo en China, en donde han externalizado las fases de procesamiento.

\section{Notas sobre las relaciones de intercambio y el Intercambio Ecológico Desigual}

La relación de intercambio entre dos países expresa hasta qué punto el comercio es beneficioso para cada parte. Desde la Economía Ecológica, una manera recurrente de estudiar este fenómeno es comparar el precio medio por material exportado con el precio medio por material importado. En el caso de América Latina, se observa que durante todo el período analizado el precio por unidad de peso de las importaciones siempre ha sido muy superior al de las exportaciones. De hecho, a lo largo del tiempo esta brecha (en términos absolutos) ha crecido: en 1966 la región pagaba 0,5 \$ por cada $\mathrm{kg}$ importado mientras que vendía a 0,1 \$; en 2016, pagaba 1,6 \$ y vendía a 0,6 \$. En otras palabras, América Latina tiene que vender muchos más recursos para poder pagar sus importaciones.

En la Figura 9 se muestra la relación de intercambio distinguiendo las regiones del mundo con las que comercian los países de América Latina. La relación con Europa es la más lesiva: por unidad de peso, las importaciones europeas se pagan entre 6 y 8 veces más caras que las exportaciones. La relación también ha sido desventajosa con la mayoría de las regiones del mundo salvo con África y con Asia Central hasta la década de 1980. Desde entonces la relación con estas regiones también se ha balanceado. Dicho de otra forma, hoy en día América Latina no comercia de manera 'ventajosa' con ninguna región del mundo, lo que nos indica una profundización del patrón de especialización basado en la explotación y exportación de recursos naturales, como se mostró más arriba. 
a)

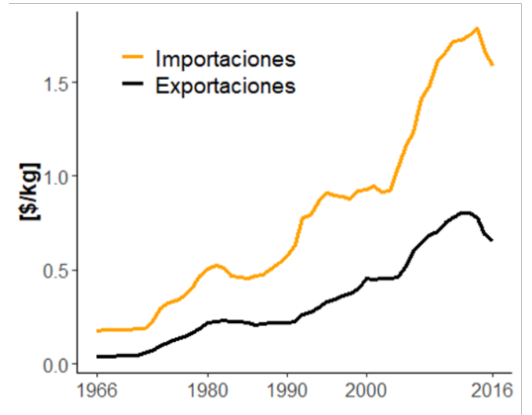

b)

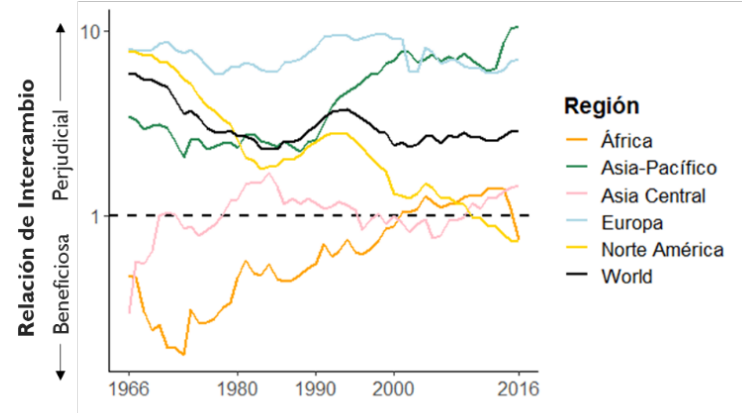

Figura 9. (a) Precio de las importaciones y las exportaciones por unidad material (\$ constantes por kg). (b) Relación de intercambio con las diferentes regiones del mundo. Nota: Un valor superior a uno indica una relación desfavorable y viceversa. Fuente: Elaboración propia (ver Patrones regionales de especialización).

La relación de intercambio de América Latina con el resto del mundo se ha mantenido relativamente estable, fruto de la combinación de comportamientos regionales diferentes: mientras que la relación con África y Asia ha empeorado, la relación con América del Norte ha mejorado. No obstante, se observa que la relación de intercambio mejoró ligeramente hasta bien entrada la década de 1980. En el largo plazo, Ocampo \& Parra (2003) encontraron un deterioro escalado de los términos de Intercambio de las commodities desde 1920, aunque menos claro entre 1920 y 1970, y una tendencia evidente de deterioro a partir de 1980. Sin embargo, al analizar el comercio agroalimentario de la región, Pinilla \& Aparicio (2015) confirman el deterioro de los precios relativos entre 1920 y 1950. No obstante, lo que está claro, es que durante el periodo de 'Industrialización Dirigida por el Estado' (c. 1930-1975) la dependencia de la región de los mercados internacionales fue mucho menor que durante la Primera Globalización y durante el periodo de apertura económica forzada por la crisis de la deuda externa de 1980 en adelante

A partir de las décadas de 1970-80, no solo se hace evidente el deterioro de los precios relativos de las materias primas (Ocampo \& Parra, 2003), sino que, además, el colapso de la política de 'industrialización dirigida', abrió la puerta a una nueva etapa de 'reorientación hacia los mercados internacionales' (Bértola \& Ocampo, 2013). Durante la Segunda Globalización, la reprimerización extractivista y el creciente deterioro de las relaciones de intercambio han marcado la pauta de las relaciones comerciales de la región con el mundo.

A principios del siglo XXI se inició una nueva etapa caracterizada por un alza en el precio de los productos básicos y una gran demanda por parte de los mercados asiáticos. En este período se consolidó la reprimarización del comercio en América Latina junto con una fuerte subida de las importaciones de productos manufacturados. El incremento en el precio de los productos básicos hizo que, no obstante, el balance comercial monetario fuese favorable. La nueva transición hacia los 
mercados asiáticos ha derivado en una gran descapitalización material, pero, eso sí, con balances comerciales monetarios saneados. Sin embargo, según nuestros resultados, y como han mostrado otros trabajos (Samaniego, Vallejo \& Martínez-Alier, 2017), esta tendencia parece que se está revirtiendo en los últimos años. Se anuncia una nueva caída en los precios de los productos primarios que potencialmente puede llevar a una situación lose-lose ya vivida en la década de 1980: aumento en las exportaciones netas de materiales con balances monetarios negativos.

La situación de desventaja secular se explica principalmente por nivel de procesamiento de los bienes comerciados. América Latina tradicionalmente ha sido importadora neta de manufacturas y exportadora neta de productos primarios, y esta tendencia se ha acentuado con el tiempo y a nivel geográfico: en la segunda mitad del siglo XX ha pasado de ser importadora neta a ser exportadora neta de productos primarios hacia el resto de las regiones periféricas del mundo, incluyendo África.

\section{Comercio y desarrollo económico}

Existe un consenso casi generalizado entre los economistas sobre el impacto positivo del comercio internacional en el desarrollo económico. Desde David Ricardo hasta las modernas teorías del comercio internacional se asume que el comercio es un juego de suma positiva en el que todas las partes ganan al sacar provecho de sus ventajas comparativas (Krugman, Obstfeld \& Melitz, 2012).

Las ventajas de la especialización no obstante han sido disputadas cuando se analizan casos como el de América Latina. La crítica más profunda y temprana, que hoy ha sido vinculada a la Economía Ecológica, es la que se encuentra en la formulación de la tesis Prebish-Singer. Esta tesis sostiene que la relación de intercambio de los países periféricos, especializados en la exportación de productos primarios, tiende a empeorar a lo largo del tiempo, limitando la capacidad de estos países para desarrollarse 7 . Por otro lado, las teorías de la 'maldición de los recursos' también abundan en esta idea, mostrando una fuerte asociación en los países de perfil extractivista con problemas sociales y políticos (Collier \& Hoeffler, 2005; Ross, 2013; Wenar, 2015).

Con el tiempo, la tesis Prebish-Singer ha sido matizada por algunos autores que han documentado que los términos de intercambio no siempre han sido desfavorables para los países periféricos o las commodities que exportaban (Haberler, 1957; Hadass \& Williamson, 2003; Ocampo \& Parra, 2003). Sin embargo, estas mejoras no siempre han sido beneficiosas para el desarrollo económico de las economías latinoamericanas. Williamson (2011) sostiene que la mejoría en las relaciones de intercambio durante la Primera Globalización generó un fuerte incentivo para sostener la especialización primario-exportadora y, por lo tanto, un desincentivo a la industrialización. El crecimiento económico producido durante este periodo fue menor que el experimentado por los líderes industrializados, lo que aceleró la divergencia económica de América Latina con el resto del mundo. 
En la Figura 10, observamos una clara correlación positiva entre las exportacionesfísicas y la renta por habitante a lo largo del siglo XX. Esto es, la descapitalización material que se ha documentado ha coexistido con aumentos en la renta por habitante. Sin embargo, hay dos matices importantes a esta afirmación.

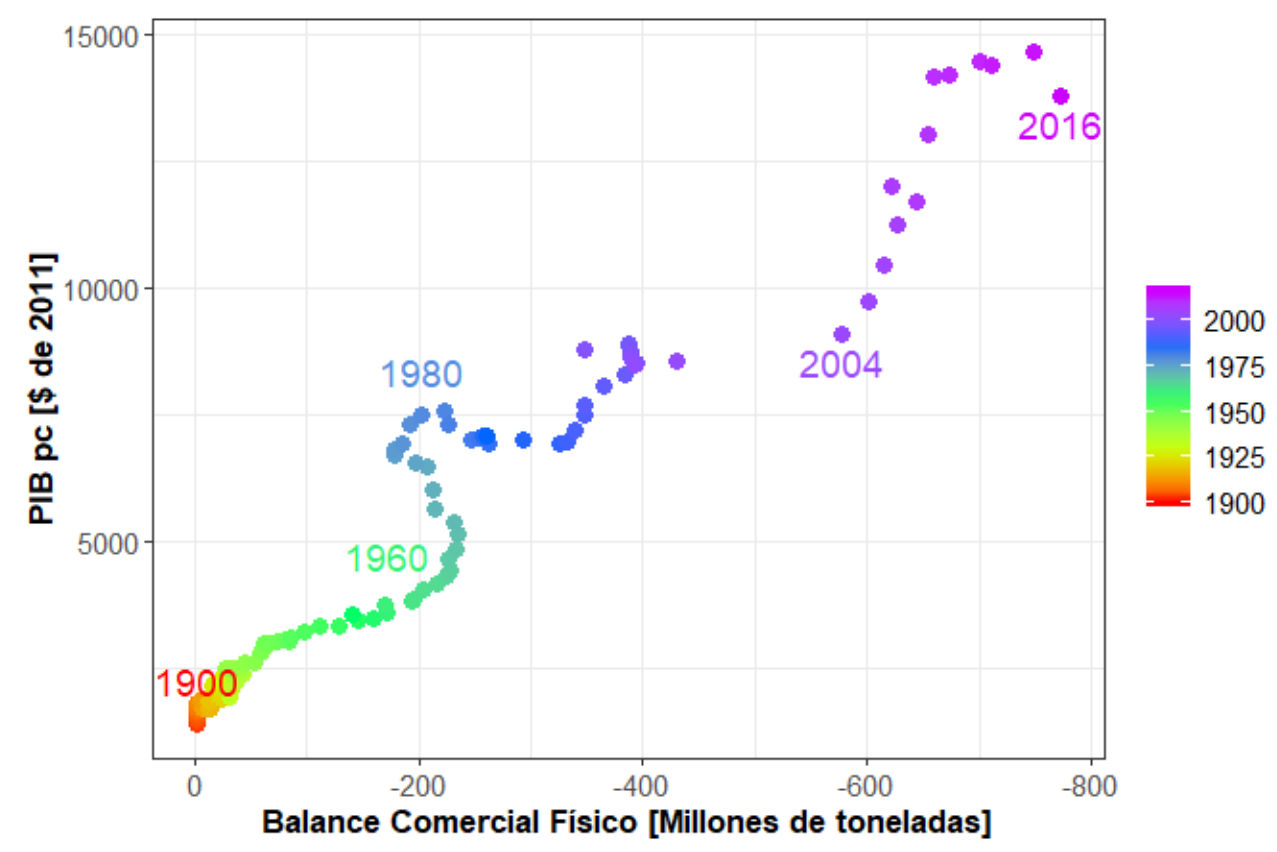

Figura 10. Relación entre el balance comercial físico y renta per cápita (dólares constantes de 2010). Fuente: Los datos de PIB han sido tomados del WB (2019), los de comercio son de elaboración propia (ver Patrones regionales de especialización).

En primer lugar, el crecimiento no siempre ha generado convergencia económica con otras regiones del mundo. En la primera mitad del siglo XX la renta por habitante en América Latina pasó de representar un $70 \%$ de la renta mundial a representar casi un $90 \%$. Sin embargo, en la década de 1980 la renta de América Latina cayó 16 puntos con respecto a la renta global. Aunque hubo crecimiento, también hubo divergencia económica con el resto de los países del mundo.

En segundo lugar, se observa que la correlación entre el aumento de las exportaciones netas y el desarrollo económico no es completamente lineal, sino que muestra discontinuidades históricas en las que es posible distinguir cuatro grandes fases:

1) Entre c. 1900 y 1950, aumentaron paralelamente el crecimiento económico, la convergencia con el resto del mundo y los déficits comerciales en términos materiales. Tras los procesos de independencia la región protagonizó un profundo proceso de cambio en sus estructuras económicas: se liberalizaron los factores productivos y tuvo lugar una rápida apertura al resto de economías. En términos históricos este período se enmarca en la Primera Globalización (1870-1930) 
y la primera etapa de las políticas de Crecimiento Liderado por el Estado (1930-1950), y se caracteriza por la presencia destacada de la región en los mercados internacionales como exportador de bienes agropecuarios. Aunque la evolución de los precios relativos de estos productos fue positiva durante esa etapa (Pinilla \& Aparicio, 2015), su volatilidad limitó el desarrollo de la región aumentando la divergencia con los países industrializados (Hadass \& Williamson, 2003; Blattman, Hwang \& Williamson, 2003, 2004, 2007; Williamson, 2008).

2) Entre c. 1950-1980 tuvo lugar un crecimiento económico acelerado sin que aumentasen sustancialmente las exportaciones netas de materiales. De hecho, en 1981, justo antes de la crisis de la deuda, la renta media de América Latina superó por primera vez la renta media global. Durante este período tuvo lugar la consolidación de la política de desarrollo hacia dentro en el contexto de la 'Edad de Oro' del crecimiento económico (c. 1950-1972). Sin embargo, este modelo de desarrollo entró en crisis. Por un lado, debido a factores externos como la crisis del petróleo. Por otro lado, por un fracaso en ciertas políticas desarrollistas. Las industrias de la región se volvieron adictas a subsidios originalmente diseñados para ayudar temporalmente al despegue de ciertos sectores. Con el aumento del precio de algunos recursos y la competencia de nuevos países asiáticos la producción industrial se volvió cada vez menos competitiva (Fajnzylber, 1983).

3) Tras la crisis del modelo desarrollista se abrió un período de aperturismo comercial y desregulación económica en el contexto de reformas estructurales muchas de ellas impuestas por organizaciones financieras internacionales. En perspectiva, observamos que la década de 1980, la de la 'utopía neoliberal', usando la expresión de Héctor Pérez (2018), fue especialmente trágica: la convergencia con el resto del mundo se desplomó a niveles de principios de siglo, las tasas de crecimiento se ralentizaron y, sin embargo, las exportaciones netas siguieron creciendo. El continente se empobreció a la vez que se descapitalizaba ambientalmente.

4) Desde el año 2003 se inició una fase similar a la de principios del siglo XX: crecimiento económico y convergencia con fuerte descapitalización material. Durante este período, gobiernos de izquierdas, en muchos casos de corte indigenista, ascendieron al poder criticando el modelo extrativista y la reprimarizacion de la región. Sin embargo, la evolución positiva coyuntural de los precios relativos les permitió beneficiarse de las rentas generadas por las exportaciones de productos básicos con precios al alza (Gudynas, 2009). Por otro lado, como se apuntaba antes, el flujo de recursos se destina ahora mayoritariamente al eje Asia-Pacífico, hoy convertido en taller del mundo. Existen dudas de si la tendencia de aumento de los precios de los productos de exportación y de las tendencias generalizadas de crecimiento económico sigan creciendo en los próximos años (Samaniego, Vallejo \& Martínez-Alier, 2017). 


\section{REFLEXIONES FINALES}

Existe un amplio consenso a la hora de caracterizar a América Latina como una región del Sur global especializada en la provisión de energía y materiales a las metrópolis globales. Sin embargo, la base empírica que sostenía este dibujo era aún muy limitada. En este trabajo se ha cuantificado el flujo total de materiales exportados e importados por la región desde 1900 hasta la actualidad, el valor monetario de esos intercambios y se han analizado las principales características de su modelo de especialización.

Los resultados obtenidos corroboran el 'saber convencional': América Latina siempre ha sido exportadora neta de materiales y la retribución que recibe por los bienes que vende son menores de los que recibe por los bienes que compra. Sin embargo, este trabajo aporta nueva evidencia empírica que ayuda a comprender mejor el papel de América Latina en la economía biofísica global. Destacan seis grandes ideas:

1) La contribución material de América Latina no ha dejado de crecer en todo el período analizado, aunque la mayor aceleración tuvo lugar desde la década de 1980. La región ha jugado un papel determinante en la segunda fase de la conocida 'gran aceleración', sustentando el gran crecimiento del consumo de materiales a nivel global. El nivel extractivo reciente ha alcanzado niveles sin precedentes: es posible que en las últimas cuatro décadas se hayan extraído más materiales para la exportación que en toda la historia previa de la región.

2) Una particularidad de América Latina entre las regiones periféricas del mundo es su alta diversificación en la exportación de materiales: a lo largo de la historia ha sido el principal suministrador, de productos agrarios, metálicos y petrolíferos. El peso de los diferentes tipos de recursos ha variado a lo largo de la historia: a principios del siglo XX los productos agrarios y ganaderos fueron el principal rubro de exportación; entre c. 1930 y 1950 lo fue el petróleo; después de la Segunda Guerra Mundial tuvo lugar un auge sin precedentes de la exportación de metales; y con el cambio de siglo la biomasa, con manejos agrícolas muy intensivos, volvió a cobrar importancia. En cualquier caso, en todos los períodos ha persistido una fuerte diversificación extractiva que hace de la región un escenario de conflictos ambientales de todo tipo a nivel global.

3) La geografía del flujo de recursos que sale de América Latina ha cambiado sustancialmente a lo largo de la historia. Hasta finales del siglo XX, el principal flujo exportador iba dirigido a Europa y EE.UU., y existía una relación balanceada con el resto de periferias. La dirección de los flujos de exportación ha estado dominada durante la mayor parte del siglo XX por una suerte de 'colonialismo informal' que dominó el subcontinente desde el siglo XIX. En los últimos 20 años el eje Asia-Pacífico, liderado por China, se ha convertido en el principal importador de materiales. Aunque es pronto para evaluar la naturaleza de esta transformación, se vislumbran dos posibles interpretaciones: por un lado, que esté teniendo lugar un cambio en la geografía del poder global en el que China está desplazando el papel hegemónico de Estados Unidos y Europa; por otro lado, es posible que China simplemente sea un 
mero intermediario entre las tradicionales potencias del norte, y la periferia global. Por último, con el cambio de siglo, también se observa un cambio en las relaciones Sur-Sur. Por primera vez en la historia, América Latina es también exportadora neta a gran escala al resto de regiones periféricas del mundo.

4) Como era previsible, América Latina muestra una relación de intercambio desfavorable con el resto del mundo fruto de ser exportador neto de productos primario e importador neto de productos manufacturados. Esta relación ha sido más gravosa con Europa y EE.UU. A partir de la década de 1980 también se ha deteriorado con África y Asia Central.

5) A lo largo del siglo XX han aumentado tanto las exportaciones físicas netas como la renta por habitante. Sin embargo, esta relación no es exactamente lineal: durante la primera mitad del siglo y desde el año 2003, la región combinó descapitalización natural con aumento precario de la renta y la convergencia. En ambos períodos, la biomasa jugó un papel muy relevante. Entre mediados del siglo XX y la crisis de la década de 1980, coincidiendo con las políticas de 'sustitución de importaciones', se vivió una situación óptima: aumentó la renta y la convergencia económica sin tanta descapitalización natural; sin embargo, esta política pudo ser parte (no exclusiva) de la crisis que se desencadenó en 1982 en la que el país de descapitalizó ambientalmente y redujo su diferencial con la renta global.

6) Los teóricos del Intercambio Ecológico Desigual argumentan que los países más pobres del mundo son suministradores netos de materiales al resto del mundo. En efecto, lo países de América Latina, entre los más pobres del mundo, son mayoritariamente exportadores netos de materiales. No obstante, dentro de la región no se observa esta relación de un modo lineal: países muy pobres como los de Centroamérica son los principales importadores de materiales. En este sentido, la densidad poblacional parece jugar un papel clave, aunque son necesarios estudios adicionales para testar esta hipótesis.

Aunque este trabajo aporta nuevas evidencias en el debate de las "venas abiertas' de América Latina, es solo un primer paso para comprender adecuadamente el papel de la región en la economía biofísica global y, en consecuencia, en el desarrollo el Antropoceno. Existen varias preguntas abiertas que se deberán resolver en futuras investigaciones. En primer lugar, como se acaba de apuntar, es necesario estudiar con más detalle cuáles son los determinantes de la descapitalización material a nivel nacional, en los que la densidad poblacional, la dotación de recursos o factores sociopolíticos específicos seguramente jueguen un papel clave. En segundo lugar, es preciso estimar el nivel de extracción y de consumo para diferenciar no solo el suministro neto al resto del mundo sino la presión real sobre los ecosistemas de cada territorio (a través de la extracción doméstica) así como la responsabilidad de sus habitantes (a través del consumo). Esto es, es preciso estimar el resto de indicadores MFA para comprender el funcionamiento de las economías biofísicas de los países analizados. De esta forma podremos evaluar la divergencia entre los niveles de consumo y extracción de América Latina con resto del mundo. 
Por último, este trabajo solo se ha centrado en los flujos de materiales directos. La cuantificación en unidades materiales permite agregar la mayor parte de bienes consumidos por un país, pero agrega bienes con diferentes características y pondera su impacto teniendo en cuenta únicamente su peso. En trabajos sucesivos es preciso cuantificar los flujos de recursos con métricas que informen mejor de problemas ambientales específicos como la tierra y el trabajo incorporados en el comercio, los flujos de energía o los flujos de nutrientes.

\section{ANEXO METODOLÓGICO}

\section{TABLA 1}

Países que componen cada región en América Latina

\begin{tabular}{lc}
\hline REGIÓN & PAÍSES \\
\hline México & México \\
Centro & Guatemala, Honduras, El Salvador, Costa Rica, Nicaragua \\
Andinos & Bolivia, Colombia, Venezuela, Ecuador, Chile \\
Brasil & Brasil \\
Sur & Argentina, Uruguay, Paraguay \\
\hline
\end{tabular}

TABLA 2

Países que componen cada región del mundo.

REGIÓN

África
PAÍSES

Angola, Burundi, Benin, Bonaire, Burkina Faso, Botswana, Central African Rep., Côte d'Ivoire, Cameroon, Dem. Rep. of the Congo, Congo, Comoros, Cabo Verde, Djibouti, Algeria, Egypt, Eritrea, Western Sahara, Ethiopia, Fmr Ethiopia, Gabon, Ghana, Guinea, Gambia, Guinea-Bissau, Equatorial Guinea, Kenya, Liberia, Libya, Lesotho, Morocco, Madagascar, Mali, Mozambique, Mauritania, Mauritius, Malawi, Mayotte, Namibia, Niger, Nigeria, RÃ@union, Rwanda, Fmr Sudan, Sudan, Senegal, Saint Helena, Sierra Leone, Somalia, South Sudan, Sao Tome and Principe, Swaziland, Seychelles, Chad, Togo, Tunisia, United Rep. of Tanzania, Uganda, So. African Customs Union, South Africa, Zambia, Zimbabwe, Fmr Rhodesia Nyas, Fmr Tanganyika, Africa CAMEU region, nes, Other Africa, nes, Sarawak, Fmr Zanzibar and Pemba Isd, Eswatini 
Afghanistan, Neth. Antilles, Neth. Antilles and Aruba, United Arab Emirates, American Samoa, Australia, Bangladesh, Bahrain, Bhutan, China, Cook Isds, Fiji, FS Micronesia, Guam, China, Hong Kong SAR, Heard Island and McDonald Islands, Indonesia, India, India, excl. Sikkim, Br. Indian Ocean Terr., Iran, Iraq, Israel, Jordan, Japan, Cambodia, Kiribati, Rep. of Korea, Kuwait, Lebanon, Sri Lanka, China, Macao SAR, Marshall Isds, Myanmar, Mongolia, N. Mariana Isds, Malaysia, New Caledonia, Norfolk Isds, Niue, Nepal, Nauru, New Zealand, Oman, East and West Pakistan, Pakistan, Fmr Pacific Isds, Pitcairn, Philippines,

Palau, Papua New Guinea, Dem. People's Rep. of Korea, State of Palestine,

French Polynesia, Qatar, Saudi Arabia, Singapore, Solomon Isds, Syria, Thailand, Tokelau, Timor-Leste, Tonga, Tuvalu, Fmr Dem. Rep. of Vietnam, Fmr Rep. of Vietnam, Viet Nam, Vanuatu, Wallis and Futuna Isds, Samoa, Fmr Arab Rep. of Yemen, Yemen, Fmr Dem. Yemen, Peninsula Malaysia, Sabah, US Misc. Pacific Isds, Other Asia, nes, Western Asia, nes, Oceania, nes, Ryukyu Isd

Centra Alsia

Azerbaijan, Belarus, Brunei Darussalam, Georgia, Kazakhstan, Kyrgyzstan, Lao People's Dem. Rep., Russian Federation, South Georgia and the South Sandwich Islands, Fmr USSR, Tajikistan, Turkmenistan, Turkey, Uzbekistan

Azerbaijan, Belarus, Brunei Darussalam, Georgia, Kazakhstan, Kyrgyzstan, Lao People's Dem. Rep., Russian Federation, South Georgia and the South Sandwich Islands, Fmr USSR, Tajikistan, Turkmenistan, Turkey, Uzbekistan

Azerbaijan, Belarus, Brunei Darussalam, Georgia, Kazakhstan, Kyrgyzstan, Lao People's Dem. Rep., Russian Federation, South Georgia and the South Sandwich Islands, Fmr USSR, Tajikistan, Turkmenistan, Turkey, Uzbekistan

Anguilla, Argentina, Antigua and Barbuda, Bahamas, Saint Barth ̃̃@lemy, Belize, Bermuda, Bolivia (Plurinational State of), Brazil, Barbados, Cocos Isds, Chile, Colombia, Costa Rica, Cuba, Cura ̃̃ßao, Christmas Isds, Cayman Isds, Dominica, Dominican Rep., Ecuador, Falkland Isds (Malvinas), Guadeloupe,

Grenada, Guatemala, French Guiana, Guyana, Honduras, Haiti, Jamaica, Saint Kitts and Nevis, Saint Kitts, Nevis and Anguilla, Saint Lucia, Maldives, Mexico, Montserrat, Martinique, Nicaragua, Fmr Panama, excl., Canal Zone, Panama, Fmr Panama-Canal-Zone, Peru, Paraguay, El Salvador, Suriname, Saint MaartenTurks and Caicos Isds, Trinidad and Tobago, Uruguay, Saint Vincent and the Grenadines, Venezuela, Br. Virgin Isds, US Virgin Isds, LAIA, nes, Caribbean, nes, CACM, nes

CanadaGreenlandSaint Pierre and MiquelonUnited States Minor Outlying IslandsUSAUSA (before 1981)North America and Central America, nes

Others

Free Zones, Antartica, Antarctica, Fr. South Antartic Terr., Fr. South Antarctic Terr., Bunkers, Special Categories, Br. Antarctic Terr., Neutral Zone 
TABLA 3

Resumen de las fuentes utilizadas

\begin{tabular}{|c|c|c|}
\hline $\begin{array}{l}\text { FUENTES } \\
\text { (PERÍODO) }\end{array}$ & INFORMACIÓN & NOTAS \\
\hline $\begin{array}{l}\text { United Nations } \\
\text { Comtrade } \\
\text { Database (1962- } \\
\text { 2016) }\end{array}$ & $\begin{array}{l}\text { Comercio bilateral físico } \\
\text { y monetario }\end{array}$ & $\begin{array}{l}\text { En Colombia, Costa Rica, Guatemala y } \\
\text { Nicaragua la serie empieza en 1965. En El } \\
\text { Salvador y Honduras en 1963. En Uruguay } \\
\text { en } 1970 .\end{array}$ \\
\hline $\begin{array}{l}\text { Liga de Naciones } \\
\quad(1913,1920- \\
1934)\end{array}$ & Comercio físico total & $\begin{array}{c}\text { México (1925-1934), Honduras }(1921,1922, \\
\text { 1924, 1925), Nicaragua (1913), Bolivia } \\
\text { (1913, 1920-1931), Chile (1925-1934), } \\
\text { Ecuador }(1913,1920-1928,1931,1932), \\
\text { Paraguay }(1913,1920,1921,1924-1931), \\
\text { Perú (1923-1934), Venezuela (1913. 1920- } \\
\text { 1933) }\end{array}$ \\
\hline $\begin{array}{l}\text { Anuarios } \\
\text { Estadísticos } \\
\text { de Comercio } \\
\text { Exterior }\end{array}$ & Comercio físico total & $\begin{array}{c}\text { Argentina (1910-1912, 1914-1919, 1935- } \\
\text { 1962), Bolivia }(1911,1912,1914-1919, \\
\text { 1942, 1945-1950,1952-1959), Brasil } \\
(1906-1912,1914-1919,1935-1961), \text { Chile } \\
\text { (1917-1922), Colombia }(1919,1935-1962), \\
\text { Costa Rica (1901-1912, 1914-1919, 1935- } \\
\text { 1949), Ecuador (1909-1909), México (1911- } \\
\text { 19248, 1935-1962), Paraguay (1914-1916, } \\
\text { 1953-1959), Perú (1935-1962), El Salvador } \\
\text { (1909-1912, 1914-1919, 1940-1949, 1952- } \\
\text { 1962), y Venezuela }(1911,1912,1914-1919, \\
\text { 1934-1962). }\end{array}$ \\
\hline $\begin{array}{l}\text { Instituto } \\
\text { Internacional } \\
\text { de Agricultura } \\
(1928-1948)\end{array}$ & $\begin{array}{l}\text { Comercio físico } \\
\text { agropecuario }\end{array}$ & $\begin{array}{l}\text { Los datos de } 1909 \text { a } 1921 \text { no siempre son } \\
\text { consistentes con las cantidades del periodo } \\
\text { siguiente, debido diferencias grandes en } \\
\text { cantidad de productos registrados. }\end{array}$ \\
\hline Mitchell (2015) & $\begin{array}{l}\text { Series históricas para } \\
\text { una selección de países y } \\
\text { productos }\end{array}$ & $\begin{array}{l}\text { Colombia: petróleo y café; Ecuador: cacao } \\
\text { y café; Perú: algodón; Venezuela: petróleo; } \\
\text { Chile: hierro; Brasil: carbón, petróleo, } \\
\text { hierro, café, cacao, algodón, goma, azúcar; } \\
\text { Argentina: carbón, carne, lana, algodón, trigo, } \\
\text { lino y maíz; Uruguay: carne y lana. }\end{array}$ \\
\hline $\begin{array}{l}\text { Base de datos } \\
\text { WTO (2019) y } \\
\text { MOxLAD (2019) }\end{array}$ & $\begin{array}{l}\text { Índice de importaciones } \\
\text { y exportaciones en } \\
\text { comercio monetario y } \\
\text { físico por país }\end{array}$ & $\begin{array}{c}\text { Proxy para interpolar los valores no } \\
\text { disponibles }\end{array}$ \\
\hline
\end{tabular}




\section{AGRADECIMIENTOS}

Queremos agradecer la ayuda de Julio Reina (Universitat de Barcelona), Emiliano Travieso (Universidad de Cambridge) y Wilson Picado (Universidad Nacional, Costa Rica) para la reconstrucción de las series históricas de Ecuador, Uruguay y Costa Rica, respectivamente. Presentamos una versión preliminar de este trabajo en un seminario organizado por el Center for Advanced Latin American Studies en la Universidad de Costa Rica el 2 de noviembre de 2019.Agradecemos los comentarios recibidos por los asistentes y, muy especialmente, a Ronny Viales y a Anthony Goeble (Universidad de Costa Rica) por organizar el evento. Este trabajo se ha financiado con el proyecto ‘Agroecological History' RTI2018-093970-B-C31 y C33 del Ministerio de Economía y Competitividad.

\section{NOTAS}

1 En efecto, hay excepciones a esta regla. Muchos autores de la ortodoxia liberal han considerado que la especialización en productos primarios responde a las ventajas comparativas de la región y que la proliferación de este modelo de especialización es, en consecuencia, beneficioso para todas las partes. Un resumen en Cardoso (1977).

2 En este sentido es obligado mencionar las decenas de trabajos publicados en el marco de la Sociedad Latinoamericana y Caribeña de Historia Ambiental y en su revista HALAC. A modo de ejemplo: los impactos de la expansión azucarera en Cuba (Funes, 2004); el cambio forestal en Argentina (Zarrilli, 2004), el Amazonas (Pádua, 2010) o Costa Rica (Goebel, 2013); o la expansión del café en Centroamérica (Gallini, 2009; Infante-Amate \& Picado, 2018).

3 La teoría económica convencional se basa en lenguajes de valoración monetarios que no captan adecuadamente los impactos sobre el medio ambiente: el valor de mercado de un bien, sugieren los economistas ecológicos, no es indicativo del impacto ambiental que genera, es más, ni siquiera informa bien sobre su grado de escasez (Hornborg, 2012; Martínez Alier \& Muradian, 2015; Daly, 2019). La Economía Ecológica, por el contrario, utiliza métricas de valoración biofísicas, más ajustadas al 'lenguaje de la naturaleza'. En este sentido, una de sus principales contribuciones ha sido el desarrollo de metodologías estandarizadas para caracterizar la base material de los sistemas económicos.

4 Igualmente, existen estudios de carácter global en los que se analiza América Latina como una entidad territorial (p.ej., Schandl y Eisenmenger, 2006; Schaffartzik et al., 2014).

5 Obviamente esta hipótesis es totalmente plausible dada la gran cantidad de evidencias locales existentes.

Suponiendo, con un ejercicio muy simplista pero prudente, que las exportaciones previas a 1900 se mantuvieron relativamente estables a lo largo del tiempo.

7 Esta lectura fue la base para el desarrollo de teorías mucho más radicales, como las 'teorías de la dependencia' o del 'sistema mundo' que no solo corroboraban la existencia de intercambios desiguales, sino que sostenían que éstos se producían por la existencia de relaciones de poder 
desiguales que perpetuaban el desarrollo del Sur global (Frank, 1967; Emmanuel, 1972). En estudios recientes, otros autores, sin entrar en el impacto económico de este patrón de especialización, cuestionan el papel dependiente de América Latina. Sostienen que la región no fue una 'víctima pasiva' o una 'simple marioneta' de poderes exteriores, sino que sus actores internos tuvieron un papel muy relevante en las relaciones con otros países y que incluso llegaron a influir decisivamente en las economías exteriores (Topik, Marichal \& Frank, 2006).

\section{REFERENCIAS}

Bértola, L., y Ocampo, J. A. (2013). The economic development of Latin America since independence. Oxford: Oxford University Press.

Blattman, C., Hwang, J. y Williamson, J. G. (2003). The Terms of Trade and Economic Growth in the Periphery 1870-1938 (Working Paper Series No. 9940). Working Paper Series. National Bureau of Economic Research.

Blattman, C., Hwang, J. y Williamson, J. G. (2004). The Impact of the Terms of Trade on Economic Development in the Periphery, 1870-1939: Volatility and Secular Change (Working Paper Series No. 10600). Working Paper Series. National Bureau of Economic Research.

Blattman, C., Hwang, J. y Williamson, J. G. (2007). Winners and losers in the commodity lottery: The impact of terms of trade growth and volatility in the Periphery 1870-1939. Journal of Development Economics, 82(1), 156-179.

Bruckner, M., Giljum, S., Lutz, C. y Wiebe, K. S. (2012). Materials embodied in international tradeGlobal material extraction and consumption between 1995 and 2005. Global Environmental Change, 22(3), 568-576.

Cardoso, F. H. (1977). La originalidad de la copia: la CEPAL y la idea de desarrollo. Revista de la CEPAL, 4(7), 40.

Castro, S. H. y Sánchez, M. (2003). Environmental viewpoint on small-scale copper, gold and silver mining in Chile. Journal of Cleaner Production, 11(2), 207-213.

Collier, P. y Hoeffler, A. (2005). Resource rents, governance, and conflict. Journal of conflict resolution, 49(4), 625-633.

Common, M. y Stagl, S. (2005). Ecological economics: an introduction. Cambridge: Cambridge University Press.

Crespo-Marín, Z. y Pérez-Rincón, M. (2019). El metabolismo social en las economías andinas y centroamericanas, 1970-2013. sociedad y economía, (36), 53-81.

Daly, H. (2019). Some overlaps between the first and second thirty years of ecological economics. Ecological Economics, 164, 106372. 
Dittrich, M. y Bringezu, S. (2010). The physical dimension of international trade: Part 1: Direct global flows between 1962 and 2005. Ecological economics, 69(9), 1838-1847.

Dorninger, C. y Eisenmenger, N. (2016). South America's biophysical involvement in international trade: the physical trade balances of Argentina, Bolivia, and Brazil in the light of ecologically unequal exchange. Journal of Political Ecology, 23(1), 394-409.

Dorninger, C. y Hornborg, A. (2015). Can EEMRIO analyses establish the occurrence of ecologically unequal exchange? Ecological Economics, 119, 414-418.

EJOLT. (2019). Environmental Justice Organisations, Liabilities and Trade. Recuperado de http:// www.ejolt.org/

Ellis, R. E. (2009). China in Latin America: the whats and wherefores (Vol. 46). Boulder, Colorado: Lynne Rienner Publishers.

Emmanuel, A. (1972). Unequal exchange: A study of the imperialism of trade. Monthly Review Press.

Eurostat. (2018). Economic-wide Material Flow Accounts (EW-MFA). Eurostat.

Fajnzylber, F. (1983). La industrialización trunca de América Latina. Ciudad de México: Editorial Nueva Imagen.

Ferguson, N. (2005). Colossus: The rise and fall of the American empire. London: Penguin.

Fischer-Kowalski, M., y Amann, C. (2001). Beyond IPAT and Kuznets curves: globalization as a vital factor in analysing the environmental impact of socio-economic metabolism. Population and Environment, 23(1), 7-47.

Fischer-Kowalski, M., Krausmann, F., Giljum, S., Lutter, S., Mayer, A., Bringezu, S., ... y Weisz, H. (2011). Methodology and indicators of economy-wide material flow accounting: State of the art and reliability across sources. Journal of Industrial Ecology, 15(6), 855-876.

Fontana, J. (2011). Por el bien del imperio. Una historia del mundo desde 1954. Barcelona: Pasado y Presente.

Food and Agriculture Organization (FAO). (1948-1961). Anuarios internacionales de estadística agrícola (varios años). Instituto Internacional de Agricultura.

Frank, A. G. (1967). Capitalism and underdevelopment in Latin America (Vol. 93). New York: NYU Press.

Gallini, S. (2009). Una historia ambiental del café en Guatemala: la Costa Cuca entre 1830 y 1902. Guatemala: Avansco.

Galt, R. E. (2008). Pesticides in export and domestic agriculture: Reconsidering market orientation and pesticide use in Costa Rica. Geoforum, 39(3), 1378-1392. 
Giampietro,M. (2006). Comments on "The energetic metabolism of the European Union and the United States" by Haberl and colleagues: Theoretical and practical considerations on the meaning and usefulness of traditional energy analysis. Journal of Industrial ecology, 10(4), 173-185.

Giljum, S. (2004). Trade, materials flows, and economic development in the South: the example of Chile. Journal of Industrial Ecology, 8(1-2), 241-261.

Giljum, S., \& Eisenmenger, N. (2004). North-South trade and the distribution of environmental goods and burdens: a biophysical perspective. The Journal of Environment Development, 13(1), 73-100.

Giljum, S., Dittrich, M., Lieber, M., \& Lutter, S. (2014). Global patterns of material flows and their socio-economic and environmental implications: a MFA study on all countries world-wide from 1980 to 2009. Resources, 3(1), 319-339.

Goebel, A. (2013). Los bosques del "progreso". Explotación forestal y régimen ambiental en Costa Rica: 1883-1955.

González-Martinez, A. C. y Schandl, H. (2008). The biophysical perspective of a middle income economy: Material flows in Mexico. Ecological Economics, 68(1-2), 317-327.

Gudynas, E. (2009). Diez tesis urgentes sobre el nuevo extractivismo. Extractivismo, política y sociedad, 187.

Haberl, H., Wiedenhofer, D., Pauliuk, S., Krausmann, F., Müller, D. B. y Fischer-Kowalski, M. (2019). Contributions of sociometabolic research to sustainability science. Nature Sustainability, 1.

Haberler, G. (1957). Los términos de intercambio y el desarrollo económico, en Ellis, H. S. El desarrollo económico y América Latina. México: Fondo de Cultura Económica, pp. 325-351.

Hadass, Y. S. y Williamson, J. G. (2003). Terms-of-trade shocks and economic performance, 1870-1940: Prebisch and Singer revisited. Economic Development and Cultural Change, 51(3), 629-656.

Hall, C.A.S., Leon Pérez. C., Leclerc, G. (Eds.). (2000). Quantifying SustainableDevelopment. The Future of Tropical Economies. San Diego: Academic Press.

Hornborg, A. (2012). Global ecology and unequal exchange: fetishism in a zero-sum world. New York: Routledge.

Houghton, R. A., Lefkowitz, D. S., \& Skole, D. L. (1991). Changes in the landscape of Latin America between 1850 and 1985 I. Progressive loss of forests. Forest Ecology and Management, 38(3-4), 143-172.

Hurtt, G. C., Chini, L. P., Frolking, S., Betts, R. A., Feddema, J., Fischer, G., ... \& Jones, C. D. (2011). Harmonization of land-use scenarios for the period 1500-2100: 600 years of global gridded annual land-use transitions, wood harvest, and resulting secondary lands. Climatic change, 109(1-2), 117.

Infante-Amate, J. y Krausmann, F. (2019). Trade, ecologically unequal exchange, and colonial legacy: the case of France and its former colonies (1962-2015). Ecological economics, 156, 98-109. 
Infante-Amate, J., \& Picado, W. (2018). Energy flows in the coffee plantations of Costa Rica: from traditional to modern systems (1935-2010). Regional environmental change, 18(4), 1059-1071.

Infante-Amate, J., de Molina, M. G. y Toledo, V. M. (2017). El metabolismo social. Historia, métodos y principales aportaciones. Revibec: revista iberoamericana de economía ecológica, 27, 130-152.

Instituto Internacional de Agricultura (IIA). (1909-1947). Anuarios internacionales de estadística agrícola (varios años). Instituto Internacional de Agricultura.

Krausmann, F., Gingrich, S., Eisenmenger, N., Erb, K. H., Haberl, H. y Fischer-Kowalski, M. (2009). Growth in global materials use, GDP and population during the 20th century. Ecological economics, 68(10), 2696-2705.

Krugman, P. R., Obstfeld, M. y Melitz, M. J. (2012). International Economics: Theory \& Policy. Boston: Pearson Education.

Larrea, C. y Warnars, L. (2009). Ecuador's Yasuni-ITT Initiative: Avoiding emissions by keeping petroleum underground. Energy for Sustainable Development, 13(3), 219-223.

Lassaletta, L., Billen, G., Grizzetti, B., Anglade, J., \& Garnier, J. (2014). 50 year trends in nitrogen use efficiency of world cropping systems: the relationship between yield and nitrogen input to cropland. Environmental Research Letters, 9(10), 105011.

League of Nations (1926/44). Statistical Yearbook of the League of Nations (several years). League of Nation: Geneva.

Li, F. (2015). Unearthing conflict: corporate mining, activism, and expertise in Peru. United States: Duke University Press.

Malhi, Y., Roberts, J. T., Betts, R. A., Killeen, T. J., Li, W. y Nobre, C. A. (2008). Climate change, deforestation, and the fate of the Amazon. science, 319(5860), 169-172.

Malm, O., Pfeiffer, W. C., Souza, C. M. y Reuther, R. (1990). Mercury pollution due to gold mining in the Madeira River basin, Brazil. Ambio, 19(1), 11-15.

Manrique, P. L. P., Brun, J., González-Martínez, A. C., Walter, M. y Martínez-Alier, J. (2013). The biophysical performance of Argentina (1970-2009). Journal of Industrial Ecology, 17(4), 590-604.

Martínez-Alier, J. y Muradian, R. (Eds.). (2015). Handbook of ecological economics. Cheltenham, UK: Edward Elgar Publishing.

Mitchell, B. (Ed.). (2013). International historical statistics, 1750-2010. London: Palgrave/Macmillan.

Funes, R.F. (2004). De bosque a sabana: azúcar, deforestación y medio ambiente en Cuba, 1492-1926. Madrid: Siglo XXI.

MOxLAD (2019). Base de datos de Historia Económica del América Latina. Recuperado de http:// moxlad.cienciassociales.edu.uy/ 
Muradian, R., Walter, M. y Martinez-Alier, J. (2012). Hegemonic transitions and global shifts in social metabolism: Implications for resource-rich countries. Introduction to the special section. Global environmental change, 22(3), 559-567.

Naredo, J. M. (2010). Raíces económicas del deterioro ecológico y social. Madrid: Siglo XXI Editores.

Ocampo, J. A. (2017). Commodity-led development in Latin America. International Development Policy Revue internationale de politique de développement, 9(9), 51-76.

Ocampo, J. A. y Parra, M. (2010). The terms of trade for Commodities since the mid-19th century. Revista de Historia Econ\&oacute;mica/Journal of Iberian and Latin American Economic History (Second Series), 28(1), 11-43.

Ocampo, J. A. y Parra, M. Á. (2003). Los términos de intercambio de los productos básicos en el siglo XX. Revista de la CEPAL, 79, 7-35.

O'Rourke, K. H. y Williamson, J. G. (1999). Globalization and history: the evolution of a nineteenthcentury Atlantic economy. Cambridge, Massachusetts. London: MIT press.

Pádua, J. A. (2010). European colonialism and tropical forest destruction in Brazil. Environmental history: as if nature existed, 130-50.

Pérez Brignoli, H. (2018). Historia global de América Latina. Del siglo XXI a la independencia. Madrid: Alianza Editorial.

Pérez-Rincón, M. A. (2006). Colombian international trade from a physical perspective: Towards an ecological "Prebisch thesis". Ecological Economics, 59(4), 519-529.

Pinilla, V., y Aparicio, G. (2015). Navigating in Troubled Waters: South American Exports of Food and Agricultural Products, 1900-1950. Revista de Historia Económica-Journal of Iberian and Latin American Economic History, 33(2), 223-255.

Prebisch, R. (1981). Capitalismo periférico. Crisis y transformación. México: Fondo de Cultura Económica.

Ricaurte Greene, B. R. (2012). El impacto ecológico del comercio ecuatoriano: flujos de materiales con los Estados Unidos, la Unión Europea y China (Tesis de Maestría). Quito: FLACSO Sede Ecuador.

Rice, J. (2007). Ecological unequal exchange: Consumption, equity, and unsustainable structural relationships within the global economy. International Journal of Comparative Sociology, 48(1), 43-72.

Ross, M. L. (1999). The political economy of the resource curse. World politics, 51(2), 297-322.

Ross, M. L. (2013). The oil curse: How petroleum wealth shapes the development of nations. Princeton, New Jersey: Princeton University Press. 
Russi, D., Gonzalez-Martinez, A. C., Silva-Macher, J. C., Giljum, S., Martínez-Alier, J. y Vallejo, M. C. (2008). Material flows in Latin America: a comparative analysis of Chile, Ecuador, Mexico, and Peru, 1980-2000. Journal of Industrial Ecology, 12(5-6), 704-720.

Sachs, J. D. y Warner, A. M. (2001). The curse of natural resources. European economic review, 45(4-6), 827-838.

Samaniego, P., Vallejo, M. C. y Martínez-Alier, J. (2017). Commercial and biophysical deficits in South America, 1990-2013. Ecological Economics, 133, 62-73.

Schaffartzik, A., Mayer, A., Gingrich, S., Eisenmenger, N., Loy, C. y Krausmann, F. (2014). The global metabolic transition: Regional patterns and trends of global material flows, 1950-2010. Global Environmental Change, 26, 87-97.

Schandl, H. y Eisenmenger, N. (2006). Regional patterns in global resource extraction. Journal of Industrial Ecology, 10(4), 133-147.

Schandl, H., Fischer-Kowalski, M., West, J., Giljum, S., Dittrich, M., Eisenmenger, N., ... others. (2017). Global Material Flows and Resource Productivity. Assessment Report for the UNEP International Resource Panel. Pre-publication final draft.

Scheidel, A., Del Bene, D., Liu, J., Navas, G., Mingorría, S., Demaria, F., Avila, S., Roy,B., Ertör, I., Temper, L., Martinez-Alier. J. (2020). Environmental Conflicts and Defenders: A Global View. Global Environmental Change (on-line first: https://doi.org/10.1016/j.gloenvcha.2020.102104).

Steffen, W., Broadgate, W., Deutsch, L., Gaffney, O. y Ludwig, C. (2015). The trajectory of the Anthropocene: the great acceleration. The Anthropocene Review, 2(1), 81-98.

Topik, S., Marichal, C. \& Frank, Z. (2006). From silver to cocaine: Latin American commodity chains and the building of the world economy, 1500-2000. Duke University Press.

Vallejo, M. C. (2010). Biophysical structure of the Ecuadorian economy, foreign trade, and policy implications. Ecological Economics, 70(2), 159-169.

Vallejo, M. C., Pérez Rincón, M. A. y Martinez-Alier, J. (2011). Metabolic profile of the Colombian Economy from 1970 to 2007. Journal of industrial Ecology, 15(2), 245-267.

Wenar, L. (2015). Blood oil: Tyrants, violence, and the rules that run the world. Oxford: University Press. Oxford.

West, J. y Schandl, H. (2013). Material use and material efficiency in Latin America and the Caribbean. Ecological Economics, 94, 19-27.

Wiedmann, T. O., Schandl, H., Lenzen, M., Moran, D., Suh, S., West, J. y Kanemoto, K. (2015). The material footprint of nations. Proceedings of the National Academy of Sciences, 112(20), 6271-6276.

Williamson, J. (2008). Globalization and the Great Divergence: terms of trade booms, volatility and the poor periphery, 1782-1913. European Review of Economic History, 12(3), 355-391. https://doi. org/10.1017/s136149160800230x 
Williamson, J. G. (2011). Trade and poverty: when the Third World fell behind. Cambridge, Massachusetts: MIT press.

World Bank (WB). (2019). Data Bank. World Development Indicators. Recuperado de https://databank. worldbank.org/reports.aspx?source=world-development-indicators

World Trade Organization (WTO). (2019). WTO Data Portal. Recuperado de http://stat.wto.org/Home/ WSDBHome.aspx

WU Vienna (2020). Material flows by material group, 1970-2017. Visualisation based upon the UN IRP Global Material Flows Database. Vienna University of Economics and Business. Online available at: materialflows.net/visualisation-centre

Zarrilli, A. G. (2004). Historia, Ambiente y Sociedad. La explotación forestal de los bosques chaqueños argentinos (1895-1948). Diálogos revista electrónica de historia, 4(2). 